\title{
CONHECIMENTO POPULAR DE PLANTAS MEDICINAIS NO MUNICÍPIO DE SÃO THOMÉ DAS LETRAS, MG
}

\author{
Local knowledge of medicinal plants in the municipality of São Thomé dlas Letras, \\ MG
}

\author{
Renata de Melo FERREIRA-LOPES ${ }^{1 *}$, Valéria Lúcia de Oliveira FREITAS ${ }^{2}$, Paulina Maria MAIA-
} BARBOSA $^{3}$

\footnotetext{
1 Universidade Federal de Minas Gerais (UFMG) - Brasil, 2 Secretaria de Desenvolvimento Econômico, Ciência, Tecnologia e Ensino Superior (SEDECTES) - Brasil, 3 Departamento de Biologia Geral, Laboratório de Limnologia e Educação Ambiental, Universidade Federal de Minas Gerais (UFMG) - Brasil..*renatademeloferreira@yahoo.com.br
}

Submitted: 01/09/2020; Accepted: 27/10/2020; Published: 10/01/2021

\section{RESUMO}

Estudos etnobotânicos podem subsidiar projetos de bioprospecção e conservação de plantas nativas com propriedades medicinais, pois, através da utilização dos recursos vegetais como medicamentos, a própria população pode tornar efetiva a sua proteção. Nesse sentido, o objetivo deste trabalho foi estudar o conhecimento popular de moradores de São Thomé das Letras, MG, na bacia do Alto Rio Grande, sobre as espécies vegetais medicinais nativas da região. $O$ público-alvo para o levantamento etnobotânico foram moradores da área urbana e rural do município e de seu entorno, que detêm algum conhecimento especial a respeito de plantas medicinais nativas da região. Foram realizadas entrevistas semiestruturadas com 20 informantes e turnês guiadas com seis deles, em Cerrado sentido restrito, Cerrado Rupestre, campos, fragmentos de floresta estacional semidecidual e beiras de estrada, além de quintais com espécies nativas cultivadas. Ao todo foram citadas 87 espécies, pertencentes a 46 famílias botânicas. Fabaceae e Asteraceae foram as famílias com o maior número de espécies citadas. As categorias de doenças com maior representatividade foram doenças da pele (20\%), transtornos do sistema genito-urinário (17\%) e transtornos do sistema respiratório (14\%). As espécies que tiveram os mesmos usos mencionados por 10 ou mais informantes foram Stryphnodendron adstringens (barbatimão) Croton antisyphiliticus (curraleira, pé-de-perdiz) Vernonia polyanthes (assa-peixe), Leonurus sibiricus (isope), Rudgea viburnoides (douradinha-do-mato), Palicourea rigida (douradinha), Jacaranda decurrens (carobinha), Dorstenia brasiliensis (carapiá) e Lychnophora pinaster (arnica). Os dados gerados por esta pesquisa poderão orientar propostas de comercialização, pelos próprios moradores de São Thomé das Letras, de produtos medicinais oriundos de sua flora nativa, que podem constituir uma alternativa econômica para o município e uma estratégia para diminuir a pressão de coleta sobre as plantas em seu hábitat natural.

PALAVRAS CHAVE: etnobotânica, bioprospecção, Cerrado, conservação ambiental, floresta semidecídua.

\footnotetext{
ABSTRACT

Ethnobotanical studies can support bioprospecting and conservation projects of native plants with medicinal properties - through the use of plant resources such as medicines, the population itself can make their protection effective. In this sense, the objective of this work was to study the local knowledge of residents of São Thomé das Letras, MG, in the Alto Rio Grande basin, about the medicinal plant species native to the region. Semi-structured interviews were conducted with 20 residents from the urban and rural area of the municipality and its surroundings, who had some
} 
special knowledge regarding native medicinal plants. Guided tours with six informants, in restricted sense Cerrado, Cerrado Rupestre, fields, fragments of semideciduous seasonal forest and roadsides, in addition to backyards with cultivated native species, were made. Altogether 87 species were cited, belonging to 46 botanical families. Fabaceae and Asteraceae were the families with the highest number of species mentioned. The most representative categories of diseases were skin diseases (20\%), disorders of the genitourinary system (17\%) and disorders of the respiratory system (14\%). The species that had the same uses mentioned by 10 or more informants were Stryphnodendron adstringens Mart. (Coville) (barbatimão) Croton antisyphiliticus (curraleira, ervade-perdiz) Vernonia polyanthes (assa-peixe), Leonurus sibiricus (isope), Rudgea viburnoides (douradinha-do-mato), Palicourea rigida (douradinha), Jacaranda decurrens (carobinha), Dorstenia brasiliensis (carapiá) and Lychnophora pinaster (arnica). The data generated by this research may guide commercialization proposals, by the residents of São Thomé das Letras, of medicinal products from their native flora, would constitute an economical alternative for the municipality and would reduce the collection pressure on plants in their natural habitat.

KEYWORDS: ethnobotany, bioprospection, Cerrado, environmental conservation, semideciduous seasonal forest.

\section{INTRODUÇÃO}

Segundo Alcorn (1995), cerca de 80\% das pessoas confiam na medicina tradicional. Por sua vez, o artigo 10 da Convenção sobre Diversidade Biológica (CDB), um dos mais relevantes tratados ambientais do mundo, preconiza a utilização sustentável da biodiversidade de maneira a "proteger e encorajar a utilização costumeira de recursos biológicos de acordo com práticas culturais tradicionais compatíveis com as exigências de conservação ou utilização sustentável” (BRASIL, 2000, p. 13). Entretanto, o Brasil, que possui uma biodiversidade extremamente rica, sendo responsável por aproximadamente $20 \%$ de todas as espécies vivas do planeta (BOLZANI et al., 2010), registrava, segundo pesquisas de Gottlieb e colaboradores (1996), apenas 1\% de sua flora conhecida quimicamente. Não obstante constituir-se como fonte para a síntese de novos fármacos, estudos sobre o conhecimento e uso, pelas populações locais, dos recursos naturais, são importantes também para o manejo e conservação dos mesmos (BERKES et al., 2000; HANAZAKI, 2003).

Um estudo sobre aprovação de medicamentos, realizado por Newman e Cragg (2012), aponta que cerca de 64\% deles continha um produto natural envolvido em seu desenvolvimento. Em nível global, o uso de fitoterápicos foi oficialmente reconhecido pela Organização Mundial de Saúde em 1978. O Brasil, por sua vez, aprovou a Política Nacional de Plantas Medicinais e Fitoterápicos em 2006 (BRASIL, 2006b). Nesse sentido, o reconhecimento da medicina popular como conhecedora de um patrimônio genético inestimável é o primeiro passo para a integração do sistema médico popular ao moderno (MACIEL et al., 2002). 
Na região do Alto Rio Grande, ao sul de Minas Gerais, estudos florísticos e fitossociológicos, especialmente em áreas de florestas estacionais semideciduais, oferecem subsídios para políticas de conservação da Mata Atlântica (RODRIGUES e CARVALHO, 2008). Entretanto, são poucos os trabalhos relativos ao estudo de espécies vegetais úteis nessa região (BOTREL et al., 2004; CARVALHO e RODRIGUES, 2005; RODRIGUES e CARVALHO, 2001, 2007, 2008, 2010, 2015; RODRIGUES et al., 2002; FERREIRA et al., 2013). Considerada de importância biológica muito alta devido à presença de campos rupestres que abrigam frágil vegetação, sendo a mineração de quartzito e o turismo desordenado as pressões antrópicas mais importantes (DRUMMOND et al., 2005), a região onde se insere o município de São Thomé das Letras foi objeto de recomendações específicas para a realização de inventários de flora e fauna e criação de unidades de conservação. Dentro desse contexto, o objetivo deste trabalho foi estudar o conhecimento popular de moradores de São Thomé das Letras, MG, sobre as espécies vegetais medicinais locais.

\section{METODOLOGIA}

\section{1 Área de estudo}

O município de São Thomé das Letras está inserido na Região Sul do estado de Minas Gerais, no domínio da porção ocidental da serra da Mantiqueira, bacia do Rio Grande, sub-bacia do Rio Verde, a 336 km de Belo Horizonte. Possui altitude média de $1290 \mathrm{~m}$, pluviosidade de 1.456 a $1.650 \mathrm{~mm}$, temperatura média de $19^{\circ} \mathrm{C}$, mínima de $15^{\circ} \mathrm{C}$ e máxima de $26^{\circ} \mathrm{C}$ (INMET, 2011). A cobertura vegetal da região de São Thomé das Letras constitui-se de uma área de transição entre as florestas semidecíduas do Sudeste e Sul do país e o Cerrado do Brasil Central, incluindo aí o Cerrado Rupestre, as formações campestres como o Campo Sujo, o Campo Limpo e o Campo Rupestre (EITEN, 1972; RIBEIRO e WALTER, 2008; OLIVEIRA-FILHO e FLUMINHAN-FILHO, 1999).

Sua economia está fundamentada em três atividades principais: o extrativismo mineral (Fig. 1), que ocupa até $70 \%$ da população ativa, a agropecuária e o turismo (DESCHAMPS et al., 2002), já que a cidade se insere num complexo mineralógico de quartzito (pedra são tomé) e possui um patrimônio histórico datado do século XVIII (D’AURIA, 2000), além de expressivas formações naturais e arqueológicas (LOPES e RUCHKYS, 2015). 


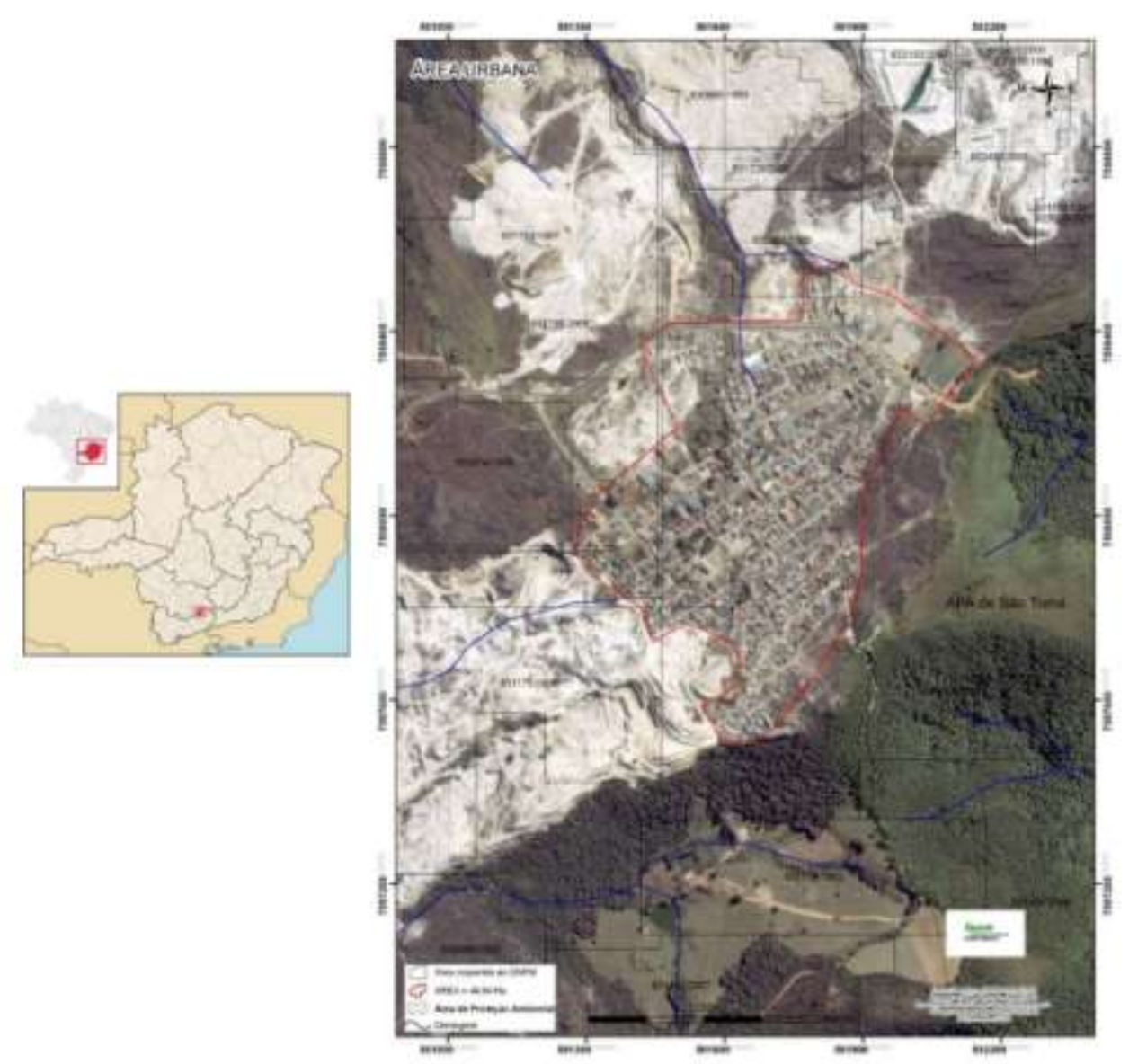

Figura 1. São Thomé das Letras, MG: à esquerda, localização do município (destacado em vermelho) no estado de Minas Gerais (Fonte: Wikipédia). À direita, vista aérea da Serra de São Thomé das Letras, área da zona urbana do município circulada em vermelho e cursos d'água destacados em azul (Fonte: Geominas e Departamento Nacional de Produção Mineral - DNPM, 2009).

\subsection{Coleta de dados}

O público-alvo para o levantamento etnobotânico foram moradores da área urbana e rural do município de São Thomé das Letras e seu entorno, que detêm algum conhecimento a respeito de plantas medicinais nativas da região. A seleção dos participantes da pesquisa foi realizada por meio da técnica bola-de-neve, que consiste em localizar um ou mais informantes-chave, que por sua vez indicam outros candidatos que poderão participar da pesquisa (MARTIN, 1995; BERNARD, 1996). Em função de trabalhos científicos desenvolvidos pelas autoras na comunidade desde 2006, já eram conhecidos alguns informantes-chave, portanto, as primeiras visitas domiciliares exploratórias foram priorizadas intencionalmente (THIOLLENT, 2011).

As técnicas utilizadas para a coleta de informações foram entrevistas semiestruturadas, que constavam de perguntas já formuladas, como espécie vegetal de uso medicinal, nomes populares, hábito da planta, indicação, partes utilizadas e forma de 
utilização e outras que surgiram naturalmente durante a entrevista, permitindo liberdade aos narradores (MARTIN, 1995).

Os participantes da pesquisa foram entrevistados individualmente, de acordo com sua disponibilidade, entre os meses de julho de 2009 e setembro de 2011, sendo as falas dos participantes gravadas em gravador digital e posteriormente transcritas. As entrevistas foram concedidas após assinatura, pelos participantes, do Termo de Consentimento Livre e Esclarecido, de acordo com as normas do Comitê de Ética e Pesquisa da Universidade Federal de Minas Gerais (CAAE - 0377.0.203.000-10).

As áreas naturais para observação e coleta das plantas citadas nas entrevistas foram indicadas por alguns participantes, que se dispuseram a realizar turnês guiadas para obtenção das plantas e seu registro fotográfico. Para tanto, foram amostradas diferentes formações fisionômicas: Cerrado sentido restrito, cerrado rupestre, campos, fragmentos de floresta estacional semidecidual e beiras de estrada, além de quintais que continham espécies nativas cultivadas (Tab. 1, Fig. 2).

Foi utilizada a Listagem Livre, adaptada de Weller e Kimball Romney (1988), que consiste em uma lista de espécies das plantas citadas durante entrevistas anteriores, para apresentação aos participantes subsequentes, juntamente com fotografias das plantas coletadas em saídas de campo anteriores ou presentes na literatura. Esse procedimento visou suprir a não observação de plantas em campo, citadas pelos participantes que não se dispuseram a realizar as caminhadas livres, assim como facilitou a identificação de plantas citadas nas entrevistas, mas não encontradas em campo.

A identificação taxonômica das plantas foi realizada com base em literatura especializada, auxílio de especialistas e comparações com materiais dos herbários BHCB (ICB/UFMG) e HXBX (CETEC). A nomenclatura utilizada para as famílias seguiu a classificação utilizada pela APG IV (2016). Foram incluídas nas análises as morfo-espécies das plantas não identificadas, e as amostras férteis foram incorporadas ao herbário HXBX.

As indicações terapêuticas das espécies citadas foram enquadradas nas categorias reconhecidas pela Organização Mundial da Saúde - Classificação Estatística Internacional de Doenças e Problemas Relacionados à Saúde (CID-10, 2008), com algumas modificações, sendo elas: doenças infecciosas; doenças parasitárias; doenças nutricionais, das glândulas endócrinas e do metabolismo; doenças do sistema osteomuscular e tecido conjuntivo; doenças da pele; transtornos do sistema visual; transtornos do sistema nervoso; transtornos do sistema circulatório; transtornos do sistema respiratório; transtornos do 
FERREIRA-LOPES et al. Conhecimento popular de plantas medicinais no município de São Thomé das Letras, MG.

Ethnoscientia v. 6, 2021. D.O.I.: 10.22276/ethnoscientia.v6i1.345.

sistema gastrintestinal; transtornos do sistema genito-urinário; analgésico; neoplasia; transtornos não definidos.

Tabela 1. Caracterização das áreas amostradas, município de São Thomé das Letras, MG, 2011.

\begin{tabular}{|c|c|c|c|}
\hline Áreas de Coleta & Coordenadas & Alt (m) & Caracterização da área \\
\hline $\begin{array}{l}\text { Fazenda Recreio - } \\
\text { Limite com Cruzília }\end{array}$ & $21^{\circ} 41^{\prime} 19^{\prime \prime} \mathrm{S}, 44^{\circ} 40^{\prime} 30^{\prime \prime} \mathrm{W}$ & & $\begin{array}{l}\text { Fragmento de floresta estacional } \\
\text { semidecidual, campos limpos, beira } \\
\text { de estrada e pastagens }\end{array}$ \\
\hline $\begin{array}{l}\text { Fazenda do Venilton - } \\
\text { Limite com Luminárias }\end{array}$ & $21^{\circ} 38^{\prime} 13^{\prime \prime S}, 44^{\circ} 54^{\prime} 04^{\prime \prime W}$ & 1240 & $\begin{array}{l}\text { Fragmento de floresta estacional } \\
\text { semidecidual, beira de estrada e } \\
\text { pastagens }\end{array}$ \\
\hline Vale das Borboletas & $21^{\circ} 43^{\prime} 11 \mathrm{~S}^{\prime \prime}, 45^{\circ} 00^{\prime} 10^{\prime \prime} \mathrm{W}$ & 1013 & $\begin{array}{l}\text { Fragmento de floresta estacional } \\
\text { semidecidual, fragmento de cerrado, } \\
\text { beira de estrada e pastagens }\end{array}$ \\
\hline Bairro Rural Sobradinho I & $21^{\circ} 31^{\prime} 07^{\prime \prime S}, 44^{\circ} 59^{\prime} 46^{\prime \prime W}$ & 995 & $\begin{array}{l}\text { Fragmento de floresta estacional } \\
\text { semidecidual, beira de estrada e } \\
\text { áreas de pastagens }\end{array}$ \\
\hline Bairro Rural Sobradinho II & $21^{\circ} 38^{\prime} 24^{\prime \prime S}, 44^{\circ} 51^{\prime} 54^{\prime \prime} \mathrm{W}$ & & $\begin{array}{l}\text { Fragmento de floresta estacional } \\
\text { semidecidual e quintal com espécies } \\
\text { nativas cultivadas }\end{array}$ \\
\hline Perímetro urbano & $21^{\circ} 38^{\prime} 55^{\prime \prime} \mathrm{S}, 44^{\circ} 53^{\prime} 52^{\prime \prime} \mathrm{W}$ & & $\begin{array}{l}\text { Quintal com espécies nativas } \\
\text { cultivadas }\end{array}$ \\
\hline
\end{tabular}




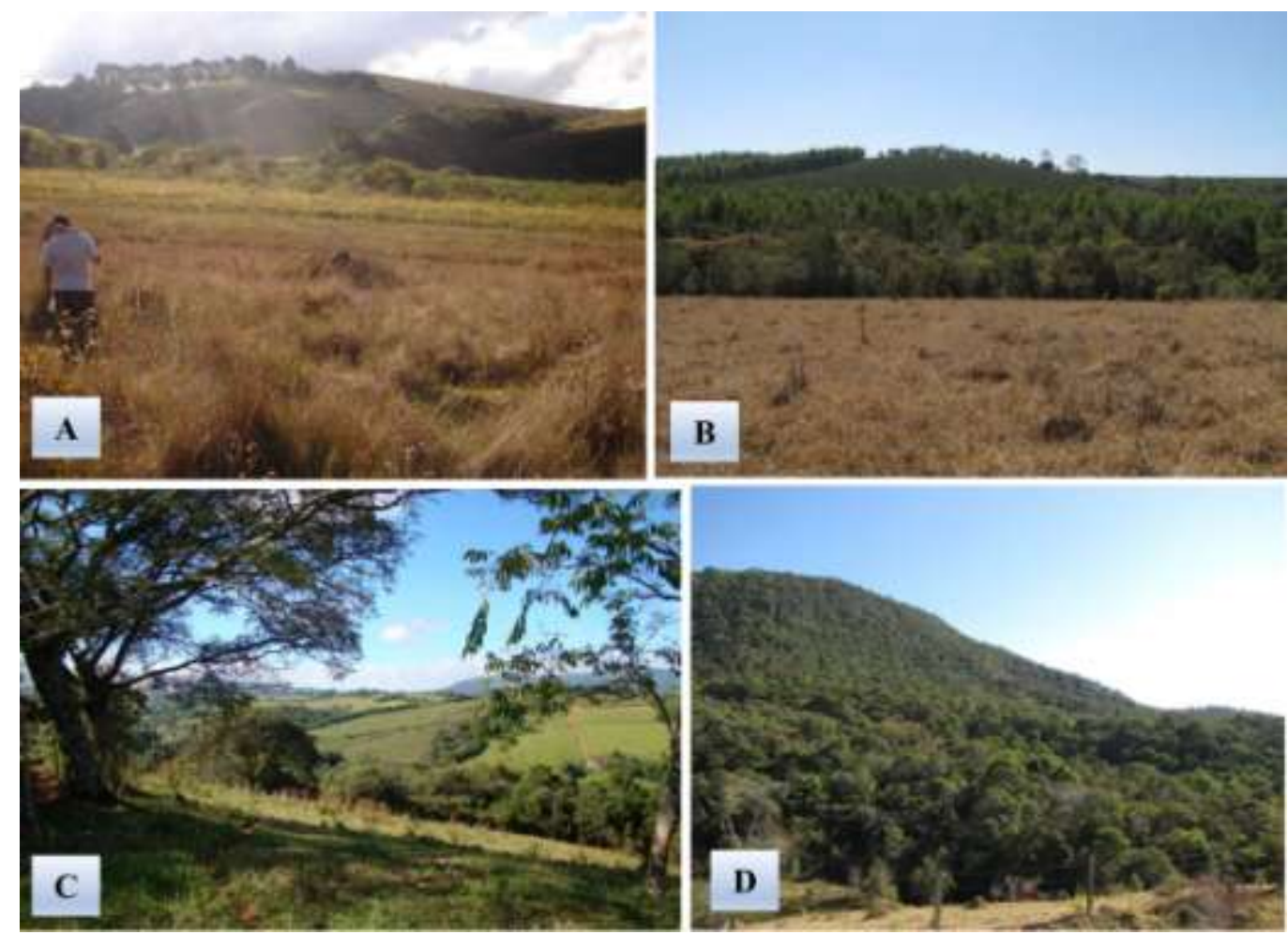

Figura 2. São Thomé das Letras, MG: A - Fazenda Recreio, limite com Cruzília, 1040m de altitude, fragmento de mata, campos limpos, beira de estrada e pastagens. B - Fazenda do Venilton, limite com Luminárias, 1240m, fragmento de mata, beira de estrada e pastagens - C - Vale das Borboletas, 1013m, fragmento de mata e cerrado, beira de estrada e pastagens. D - Bairro rural de Sobradinho I, 995m, fragmento de mata, beira de estrada e áreas de pastagens. Fonte: Laboratório de Restauração Ecológica CETEC/MG (2008).

\section{RESULTADOS E DISCUSSÃO}

Foram realizadas entrevistas semiestruturadas com 20 conhecedores de plantas medicinais nativas da região de São Thomé das Letras, em suas residências, sendo sete incursões a campo realizadas com seis informantes para observação, registro e coleta das plantas citadas. O esforço amostral, contabilizado a partir da contagem do tempo de entrevista com cada informante, foi, em média, de duas horas e 30 minutos com os informantes que não foram a campo e quatro horas com aqueles que se dispuseram a realizar as caminhadas livres.

A faixa etária dos participantes variou de 35 a 86 anos, sendo 15 mulheres e cinco homens, residentes em zonas urbanas ou rurais do município e nos limites com os municípios Luminárias e Cruzília. O número médio de filhos por participante foi de cinco e o nível de escolaridade mostrou-se bastante baixo, com $30 \%$ deles desprovidos de escolaridade e $45 \%$ com apenas o ensino primário completo. A maioria dos entrevistados é aposentada e ainda exerce trabalhos na roça como autônomos; 11 dos 20 participantes 
residem na zona rural. Apenas dois deles não são nativos da cidade ou de municípios vizinhos a São Thomé das Letras, sendo oriundos do estado de São Paulo.

Os entrevistados declaram ter adquirido conhecimento sobre a identificação e uso das plantas para uso medicinal basicamente com os seus pais e/ou avós, dois citaram a literatura e dois deles relataram que seus conhecimentos são essencialmente provenientes de orientações de espíritos. Vários informantes mencionaram a importância da fé no poder de cura das plantas, para que as propriedades das mesmas surtissem efeito contra os males. Cinquenta por cento dos entrevistados lamentou que seus filhos ou outros parentes próximos não têm interesse em aprender esse tipo de saber, o que se configura em potencial perda de conhecimento para as gerações futuras. A fala de uma informante ilustra a importância da observação e da oralidade para a aquisição deste tipo de conhecimento:

"Muita coisa se perdeu, taí se perdendo, como você vê, né? Tá morrendo com os antigo. Usar as plantas... Então, é como uma lembrança de memória, né? De vê. De criança. Mas nunca de ter o conhecimento, de ter visto esses conhecimento. A gente já em casa prestava atenção, pra aprender, pra ver. E como era regra na família o irmão maior cuidar do menor, os irmãos aprendiam a fazer chá um pro outro".

Todos os participantes da pesquisa declararam usar menos as plantas medicinais nativas para a cura das enfermidades, em relação ao que usavam os seus antepassados, seja pela facilidade de encontrar medicamentos na farmácia ou pela dificuldade de coletar as plantas em seu hábitat natural, devido à idade avançada para as caminhadas. Por esses motivos, apesar de não incluídas neste trabalho, as espécies exóticas cultivadas nos quintais foram citadas em vários momentos, para diversos fins terapêuticos.

Ao todo foram citadas 87 espécies, pertencentes a 46 famílias botânicas (Apêndice 1). Fabaceae e Asteraceae foram as famílias com maior número de espécies citadas. As categorias de doenças com maior representatividade foram doenças da pele (20\%), transtornos do sistema genito-urinário (17\%) e transtornos do sistema respiratório (14\%). A alta representatividade das doenças da pele deve-se à inclusão, nesta categoria, de plantas conhecidas como depurativas do sangue, indicadas para o "sangue grosso", que resulta em ressecamento e surgimento de pequenas feridas na pele, alergias, comichões e vermelhidão, conjunto de manifestações conhecidas localmente como "garco". Trabalhos etnobotânicos realizados no extremo norte da Serra da Mantiqueira também registraram a categoria "depurativo do sangue" como uma das mais citadas (LEITE et al., 2008). Os transtornos do sistema genito-urinário foram bem representados pelas infecções renais e pedras nos rins; e os do sistema respiratório, pelas gripes e resfriados. 
Em relação às partes vegetais utilizadas, houve maior citação de "folhas" (52,6\%), o que, segundo Martin (1995), é positivo para a conservação das espécies vegetais, uma vez que a extração não excessiva das folhas preserva o indivíduo, diferentemente de quando é necessário utilizar a casca do tronco ou pedaços de raízes, situações em que a mutilação das plantas e sua exposição à contaminação por microrganismos é grande, podendo levar à morte dos indivíduos. As principais formas de utilização das plantas foram "infusão" $(35,8 \%)$ e "decocção" (47,0\%), que não é apropriada em se tratando de partes vegetais mais tenras, já que o calor excessivo pode volatilizar ou modificar substâncias ativas que estejam presentes. Em relação ao hábito das plantas citadas, 35,6\% das espécies são herbáceas, 26,4\% são arbóreas, $21,8 \%$ são arbustivas e 16,1\% são lianas.

Várias espécies citadas são utilizadas no preparo de um açúcar medicinal dito depurativo do sangue, conhecido pela maior parte dos informantes como açúcar raizeiro, com variações especialmente na quantidade de plantas utilizadas. Por motivos de proteção do conhecimento local, sua preparação não será aqui descrita. Assim como ocorre com o açúcar raizeiro, é frequente a utilização de misturas de plantas também para xaropes, garrafadas e banhos, o que, segundo Martins e colaboradores (2000), deve ser visto com cautela, pois os constituintes químicos das plantas podem reagir entre si, trazendo efeitos diferentes do desejado.

As espécies mencionadas por nove ou mais informantes foram o Stryphnodendron adstringens (Mart.) Coville (barbatimão), Croton antisyphiliticus Mart. (curraleira, erva-deperdiz), Solanum lycocarpum A. St.-Hil. (lobeira), Echinodorus grandiflorus (Cham. \& Schltdl.) Micheli (chapéu-de-couro), Rudgea viburnoides (Cham.) Benth. (douradinha-domato), Palicourea rigida Kunth (douradinha), Vernonia polyanthes Less. (assa-peixe), Jacaranda decurrens Cham. (carobinha), Baccharis trimera (Less.) DC. (carqueja), Costus spicatus (Jack.) Sw. (caninha-de-macaco, caninha-do-brejo) (Fig.3). De acordo com Friedman et al. (1986), quanto maior for a concordância entre os informantes sobre o uso de uma planta, maior é a possibilidade de que planta citada contenha algum composto químico que justifique seu uso.

As espécies que tiveram os mesmos usos mencionados por 10 ou mais informantes foram Stryphnodendron adstringens (barbatimão), Croton antisyphiliticus (curraleira), Vernonia polyanthes (assa-peixe), Leonurus sibiricus L. (isope), Rudgea viburnoides, Palicourea rigida (douradinha), Jacaranda decurrens (carobinha), Dorstenia brasiliensis Lam. (carapiá) e Lychnophora pinaster Mart. (arnica). Essas espécies foram citadas, com usos semelhantes, em Rodrigues \& Carvalho (2001), que realizaram estudos etnobotânicos 
FERREIRA-LOPES et al. Conhecimento popular de plantas medicinais no município de São Thomé das Letras, MG.

Ethnoscientia v. 6, 2021. D.O.I.: 10.22276/ethnoscientia.v6i1.345.

de plantas medicinais em formações campestres e florestais de cinco municípios da região do Alto Rio Grande, MG. A maioria delas também foi encontrada por Botrel et al. (2004), que realizaram estudo etnobotânico no sul de Minas. Croton antisyphiliticus (curraleira) e Lychnophora pinaster (arnica) foram encontradas por Rodrigues et al. (2002), que estudaram espécies medicinais nativas usadas pela população do município vizinho de Luminárias, MG.
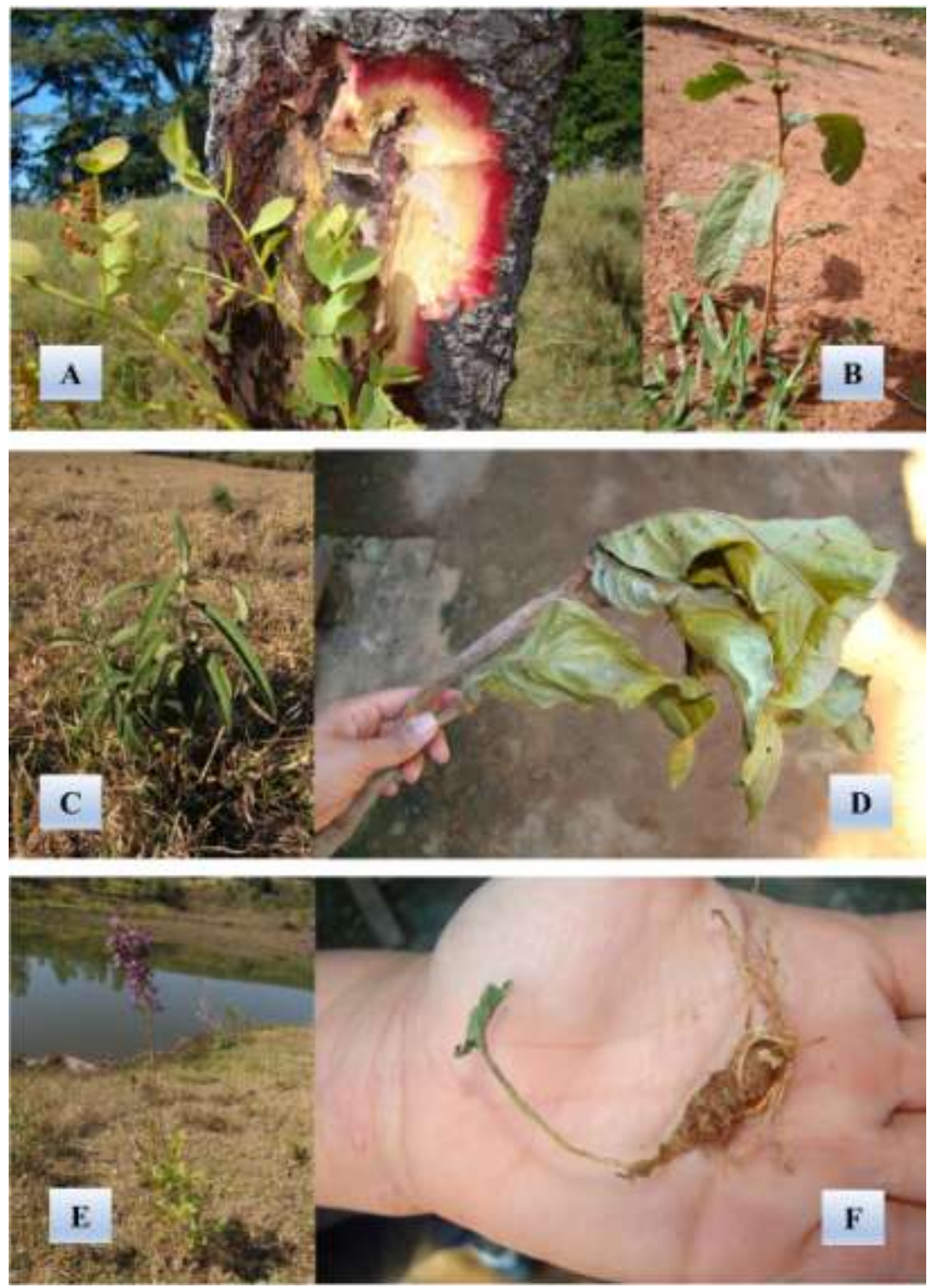

Figura 3 - Algumas espécies vegetais medicinais encontradas no município de São Thomé das Letras, Minas Gerais. A - Stryphnodendron adstringens (barbatimão), B - Croton antisyphiliticus (curraleira), C - Vernonia polyanthes (assa-peixe), D - Palicourea rigida (douradinha), E - Jacaranda decurrens (carobinha), F Dorstenia brasiliensis (carapiá). 

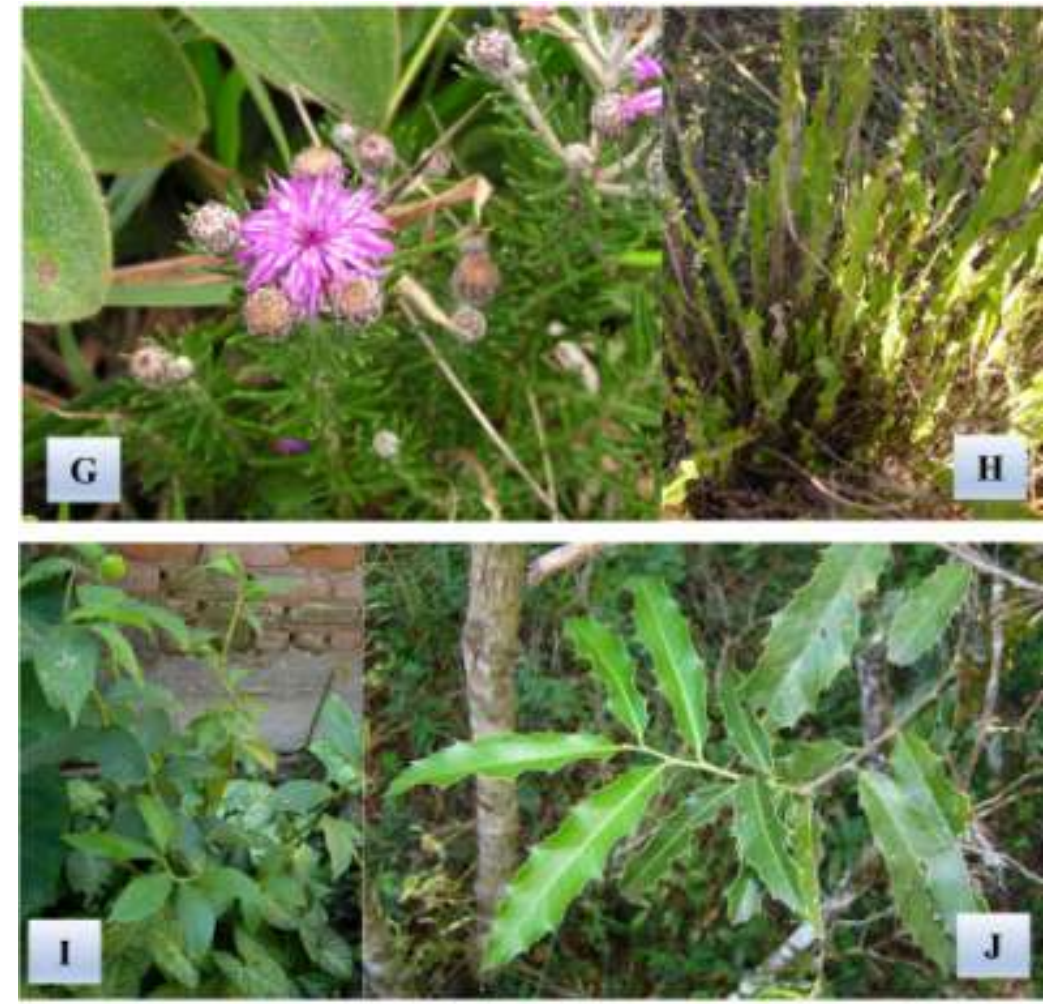

Figura 3 (continua) - G - Lychnophora pinaster (arnica), H - Baccharis trimera (carqueja), I - Costus spicatus (caninha-do-brejo, caninha-de-macaco), J - Maytenus aquifolium (espinheira-santa).

Todas as espécies vegetais mais citadas pelos informantes, inclusive aquelas com maior concordância de usos, possuem referências na literatura sobre suas propriedades medicinais, a maioria delas como indicadas pelos participantes da pesquisa, além de outras finalidades, por eles não conhecidas ou não informadas.

Dentre as espécies nativas mais citadas que possuem ações medicinais comprovadas, uma muito frequente na região (LOPES et al., 2013) é o barbatimão, Stryphnodendron adstringens. Uma recente revisão sobre as propriedades medicinais desta espécie, realizada por Souza e colaboradores (2020), corrobora os resultados obtidos por este trabalho, ao evidenciar os efeitos anti-inflamatórios, antioxidantes, antiúlcera, antimicrobianos e antiparasitários apontados pelos principais estudos sobre S. adstringens. No entanto, há necessidade de mais estudos em animais e humanos, devido aos seus efeitos tóxicos já relatados (LIMA et al., 2017).

O extrato das raízes de Croton antisyphiliticus, a curraleira ou erva-de-perdiz, é utilizado no tratamento de infecções do sistema reprodutor feminino e masculino (BARROS, 1982), além de indicada como depurativa do sangue, anti-inflamatória, contra úlceras e eczemas (CASTRO, 2006), corroborando com os levantamentos aqui realizados. 
Já Vernonia polyanthes (assa-peixe) também possui propriedades anti-ulcerogênicas (BARBASTEFANO et al., 2007) igualmente citadas no presente estudo.

Leonurus sibiricus, o isope, possui registros de atividade analgésica (ISLAM et al., 2005) e antibacteriana (AHMED et al., 2006), além de propriedades anti-inflamatórias (SHIN et al., 2009). Não foram encontradas na literatura ações desta espécie contra vermes, como levantado por este trabalho.

Galdino e colaboradores (2017) confirmaram o efeito renoprotetor da douradinhado-mato, Rudgea viburnoides, em ratos. Tal efeito sobre o sistema urinário também foi apontado pelo presente estudo. Já em relação à douradinha, Palicourea rigida, Rosa e colaboradores (2010) detectaram atividade antioxidante em extratos de suas folhas, não sendo encontradas referências na literatura, como o foi neste trabalho, sobre seu efeito no sistema urinário. A carobinha, Jacaranda decurrens, da mesma forma, possui apenas ação antioxidante descrita na literatura (CARVALHO et al., 2009).

Assim como citado no presente estudo, Ruppelt et al. (1991) detectaram propriedades analgésicas no carapiá, Dorstenia brasiliensis, além de propriedades antiinflamatórias. A aplicação tópica de substâncias das partes aéreas da arnica, Lychnophora pinaster, também apresentaram bom potencial anti-inflamatório nos trabalhos de Abreu e colaboradores (2013), sem inferências quanto ao seu potencial analgésico, levantado pela presente pesquisa. Deve-se atentar que a arnica é uma espécie ameaçada de extinção, classificada na categoria vulnerável da Lista Vermelha da Flora Ameaçada para o estado de Minas Gerais (DRUMMOND et al., 2008), o que a deve tornar alvo de projetos locais de conservação.

Os frutos da lobeira (Solanum lycocarpum) contêm alcaloides anti-inflamatórios (VIEIRA et al., 2003) tóxicos para cobaias prenhes e seus fetos (CHANG et al., 2002; SCHWARZ et al., 2007). Seus extratos demonstraram atividade contra diferentes linhagens de células tumorais humanas (MUNARI, 2014), não sendo encontradas referências na literatura sobre sua atividade antigripal, anti-hemorroida, renal ou em injúrias da pele, como citadas no presente estudo.

Já os extratos da folha de Echinodorus grandiflorus, o chapéu-de-couro, foram citados pelos informantes como benéficos para infecções renais, dentre outras utilidades. Estudos farmacológicos, por sua vez, demonstraram que os tratamentos orais com extratos das folhas desta planta apresentam efeitos anti-hipertensivos (LESSA et al., 2008), antiinflamatórios, diuréticos e cardioprotetores em ratos (MARQUES et al., 2017). 
Um trabalho de revisão sobre a carqueja, Baccharis trimera, apontou suas atividades biológicas como antioxidante, anti-inflamatório, protetora gástrica e hepática, antimicrobiana, antifúngica, antiparasitária e auxiliar na perda de peso (RABELO e COSTA, 2018). Em São Thomé das Letras, os informantes destacaram inúmeras propriedades medicinais desta planta em conformidade com o citado na literatura, como aquelas relacionadas ao fígado e a parasitoses em geral.

E, por fim, a caninha-do-brejo, Costus spicatus, que apresentou propriedades antiinflamatórias em roedores (QUINTANS et al., 2010), foi igualmente citada pelos informantes pela sua capacidade em conter inflamações.

Em 2005, a Secretaria de Ciência, Tecnologia e Insumos Estratégicos elaborou, em parceria com outros ministérios e com a colaboração de consultores e pesquisadores, uma lista das espécies vegetais já utilizadas nos serviços de saúde dos estados e municípios, além daquelas conhecidas popularmente e farmacologicamente. Esse documento subsidiou, em 2008, a construção da Relação Nacional de Plantas Medicinais de Interesse ao SUS, a RENISUS, uma lista com espécies vegetais potenciais para gerar produtos de interesse ao SUS (BRASIL, 2010). Dez espécies citadas neste trabalho estão incluídas nessa lista, são elas: Maytenus aquifolium Mart., Baccharis trimera, Casearia sylvestris Sw., Chenopodium ambrosioides L., Copaifera langsdorffii Desf., Costus spicatus, Mikania glomerata Spreng., Solanum paniculatum L., Stryphnodendron adstringens e Vernonia polyanthes (Apêndice 1). De acordo com o site do Ministério da Saúde,

\footnotetext{
"as espécies vegetais que apresentarem evidências científicas suficientes de segurança, eficácia e posologia, serão encaminhadas à ANVISA como sugestão/solicitação de inclusão na Lista de Medicamentos Fitoterápicos de Registro Simplificado”. (BRASIL, 2016, p.30-31).
}

\section{CONCLUSÃO}

Neste trabalho foi observado que a região de São Thomé das Letras ainda apresenta ambientes naturais onde são encontradas plantas nativas com fins medicinais. Há moradores antigos que guardam informações relevantes a respeito do reconhecimento de recursos vegetais nativos, adquiridos de gerações passadas. Em contrapartida, verificou-se que existe uma possível perda desse tipo de conhecimento na região estudada, pois quase $100 \%$ dos informantes afirmaram que membros de gerações precedentes possuíam conhecimento maior sobre as plantas e que as novas gerações não têm muito interesse em tal conhecimento. Algumas das razões para a falta de interesse é a atual facilidade de encontro 
de medicamentos em farmácias, ou mesmo a falta de tempo dos jovens, especialmente as mulheres, agora inseridas no mercado de trabalho.

As propriedades medicinais das plantas citadas pelos informantes coincidem com muitas listadas na literatura científica, o que denota potencial para estudos de bioprospecção para produção local, por exemplo, de fitoterápicos de baixo custo. Os fitoterápicos são reconhecidos pela Agência Nacional de Vigilância Sanitária, a ANVISA, e poderiam ser incorporados aos programas de atenção primária à saúde, do Sistema Único de Saúde de São Thomé das Letras. São mais baratos que os medicamentos alopáticos e seu cultivo promove a proteção das espécies vegetais, seja in vivo, por meio de banco de sementes e de espécimes, ou pela diminuição da pressão de coleta sobre a vegetação nativa.

A possibilidade de produzir e comercializar produtos medicinais oriundos de sua flora nativa constituiria uma alternativa econômica para São Thomé das Letras, cidade de belezas naturais, arqueológicas e históricas ímpares, porém, sacrificada pela mineração de quartzito, datada de mais de um século. Permitiria também o resguardo e aplicação de uma parte do patrimônio natural e cultural do município em benefício real de seus moradores.

\section{AGRADECIMENTOS}

À Fundação Centro Tecnológico de Minas Gerais (CETEC/MG) pela infraestrutura disponibilizada para a realização do projeto, à Fundação de Amparo à Pesquisa de Minas Gerais (FAPEMIG) pelo fornecimento de bolsa de desenvolvimento tecnológico nos primeiros anos do curso, ao Conselho Nacional de Desenvolvimento Científico e Tecnológico $(\mathrm{CNPq})$ pelo fornecimento de bolsa de doutorado nos dois últimos anos do curso, a US Fish and Wildlife Service pelo apoio ao curso de pós-graduação em Ecologia, Conservação e Manejo da Vida Silvestre (UFMG).

À pesquisadora Sylvia Meyer (CETEC/MG), pelo auxílio na identificação das plantas, aos técnicos do laboratório de Restauração Ecológica (CETEC/MG) José Carlos e Cecílio (Giru) e às bolsistas de iniciação científica Laura Botelho, Débora Bittencourt, Mariana Ubaldino e Bruna Braccini, pelo auxílio nos trabalhos de campo.

Agradecimentos especiais aos informantes, pela concessão das entrevistas.

\section{REFERENCIAS BIBLIOGRÁFICAS}

ABREU, V. G. C.; CORREA, G. M.; SILVA, T. M.; FONTOURA, H. S.; CARA, D. C.; PILÓ-VELOSO, D.; ALCÂNTARA, A. F. C. Anti-inflammatory effects in muscle injury by transdermal application of gel with Lychnophora pinaster aerial parts using 
phonophoresis in rats. BMC Complementary and Alternative Medicine, London, v. 13, n. 270, p. 1-8, 2013.

AHMED, F.; ISLAM, M. A.; RAHMAN, M. M. Antibacterial activity of Leonurus sibiricus aerial parts. Fitoterapia, Botucatu, v.77, n.4, p.316-317. 2006.

ALCORN, J. The scope and aims of ethnobotany in a Developing World. In Schultes, R. E., and von Reis, S. (eds.), Ethnobotany, Dioscorides Press, Portland. p. 23-39. 1995.

APG IV. An update of the Angiosperm Phylogeny Group - classification for the orders and families of flowering plants: APG IV. Botanical Journal of the Linnean Society, London, v.181, n. 1, p.1-20. 2016.

BARBASTEFANO, V.; COLA, M.; LUIZ-FERREIRA, A.; FARIAS-SILVA, E.; HIRUMA-LIMA, C. A.; RINALDO, D.; VILEGAS, W.; SOUZA-BRITO, A. R. M. Vernonia polyanthes as a new source of antiulcer drugs. Fitoterapia, Botucatu, v.78, n. 7-8, p.545-551. 2007.

BARROS, M. A. Flora Medicinal do Distrito Federal. Brasil Florestal, v.50, p.35-45. 1982.

BERKES, F.; COLDING, J.; FOLKE, C. Rediscovery of traditional ecological knowledge as adaptive management. Ecological applications, Botucatu, v. 10, n.5, p.1251-1262. 2000.

BERNARD, H. R. Research methods in anthropology: qualitative and quantitative approaches. American Journal of Evaluation, Florida, v.17,n. 1, p.91-92. 1996.

BOLZANI, V. S.; CASTRO-GAMBOA, I.; SILVA, D. H. S. In Comprehensive Natural Products II Chemistry and Biology; Verpoorte, R., Ed.; Elsevier: Oxford, UK, v. 3, Chapter 3.05, p.95-133. 2010.

BOTREL, R. T.; RODRIGUES, L. A.; GOMES, L; J.; CARVALHO, D. A. FONTE, M. A. Espécies vegetais nativas usadas pela população local em Ingaí, MG. Lavras: UFLA. Boletim Agropecuário, v.59, 2004. 32 p

BRASIL. Ministério da Saúde. Conferência Nacional de Medicamentos e Assistência Farmacêutica: Relatório Final: efetivando o acesso, a qualidade e a humanização na assistência farmacêutica com controle social. Conselho Nacional de Saúde. Série D. Reuniões e Conferências. Brasília, DF. 2005. 154p

BRASIL. Ministério da Saúde. RENISUS - Relação Nacional de Plantas Medicinais de Interesse ao SUS - Espécies vegetais. 2010. Disponível em http://portal.saude.gov.br/portal/arquivos/pdf/RENISUS_2010.pdf. Acessado em 29 de jan. 2012 .

BRASIL. Ministério da Saúde. Secretaria de Ciência, Tecnologia e Insumos Estratégicos. Departamento de Assistência Farmacêutica. A Fitoterapia no SUS e o Programa de Pesquisa de Plantas Medicinais da Central de Medicamentos. Série B. Textos Básicos de Saúde. Brasília, DF. 2006a. 148p 
BRASIL. Ministério da Saúde. Secretaria de Ciência, Tecnologia e Insumos Estratégicos. Departamento de Assistência Farmacêutica. Política Nacional de Plantas Medicinais e Fitoterápicos. Série B. Textos Básicos de Saúde. Brasília, DF. 2006b. 60p

BRASIL. Ministério do Meio Ambiente. Secretaria de Biodiversidade e Florestas, Diretoria de Conservação da Biodiversidade. A Convenção sobre Diversidade Biológica - CDB. Série Biodiversidade, n. 1. Brasília, DF. 2000. 30p

BRASIL. Ministério da Saúde. Secretaria de Ciência, Tecnologia e Insumos Estratégicos. Departamento de Assistência. 2012.

CARVALHO, C. A.; LOURENÇO, M. V.; BERTONI, B. W.; FRANÇA, S. C.; PEREIRA, P. S.; FACHIN, A. L; PEREIRA, A. M. S. Atividade antioxidante de Jacaranda decurrens Cham., Bignoniaceae. Revista Brasileira de Farmacognosia, Curitiba, v.19, n.2b, p.592598. 2009.

CARVALHO, L. C.; RODRIGUES, V. E. G. Levantamento florístico de plantas medicinais nativas no domínio do campo rupestre na Reserva Florestal do Boqueirão, município de Ingaí, MG. Pro Homine, Lavras, v.4, n.1, p.15-25. 2005.

CASTRO, D. L. L. Aspectos toxicológicos das plantas medicinais utilizadas no Brasil: um enfoque qualitativo no Distrito Federal. Curso de Especialização em Qualidade em Alimentos. Centro de Excelência em Turismo. Universidade de Brasília, Brasília. 2006.

CHANG, C. V.; FELÍCIO, A. C.; REIS, J. E.; GUERRA, M. O.; PETERS, V. M. Fetal toxicity of Solanum lycocarpum (Solanaceae) in rats. Journal of Ethnopharmacology, Pretoria (South Africa),v.81, n.2, p.265-269. 2002.

D'AURIA, C. A. São Thomé das Letras na encruzilhada das fontes, dos tempos e dos saberes: um estudo sobre etnografia e historicidade com registros audiovisuais. Dissertação de Mestrado. Instituto de Artes da UNICAMP, Campinas, SP. 2000.

DESCHAMPS, E.; MAIA JUNIOR, B.; COSTA, C. S.; SANTOS, M. G. V.; SCHWABE, W. K.; CARVALHO FILHO, C. A.; DAMASCENO, M. A. P.; PINTO, C. L. L. Controle Ambiental na Mineração de Quartzito São Tomé. 1. ed. Projeto Minas Ambiente. Belo Horizonte: Segrac. v. 1, 2002. 201p

DRUMMOND, G. M., MARTINS, C. S., MACHADO, A. B. M., SEBAIO, F. A. ANTONINI, Y. Biodiversidade em Minas Gerais: um atlas para sua conservação. 2 ed. Belo Horizonte, MG: Fundação Biodiversitas. 2005. 222p.

DRUMMOND, G. M; MACHADO, A. B. M.; MARTINS, C. S.; MENDONÇA, M. P.; STEHMANN, J. R. Listas vermelhas das espécies da fauna e da flora ameaçadas de extinção em Minas Gerais. 2 ed. CD-ROM, Belo Horizonte, Fundação Biodiversitas. 2008 .

EITEN, G. The Cerrado vegetation of Brazil. Botanical Review, New York, v.38, n.2, p.201-341. 1972. 
FERREIRA, F. M.; LIMA, A. L. C.; FERREIRA, R. M.; PIVARI, M. O. D. Levantamento de plantas medicinais e do conhecimento etnobotânico no município de Baependi, Minas Gerais, Brasil. MG. Biota, Belo Horizonte, v.5, n.6, p. 3-26. 2013.

FRIEDMAN, J.; YANIV, Z.; DAFNI, A.; PALEWITCH, D. A preliminary classification of the healing potencial of medicinal plants, based on a rational analysis of an ethnopharmacological field survey among bedouins in the Negev desert, Israel. Journal of Ethnopharmacology, Pretoria, South Africa, v.16, n. 2-3, p.275-287. 1986.

GALDINO, P. M.; ALEXANDRE, L. N.; PACHECO, L. F.; LINO JUNIOR R. S.; PAULA, J. R.; PEDRINO G. R.; XAVIER, C. R; FERREIRA, P. M. Nephroprotective effect of Rudgea viburnoides (Cham.) Benth leaves on gentamicin-induced nephrotoxicity in rats. Journal of Ethnopharmacology, Pretoria, South Africa v.201, n.6, p.100-107. 2017.

GOTTliEB, O. R.; KAPLAN, M. A. C.; BORIN, M. R. M. B. Biodiversidade. Um enfoque químico-biológico. Rio de Janeiro: Editora UFRJ. 1996. 267 p.

GUIVANT, J. S. Heterogeneidade de Conhecimentos no Desenvolvimento Rural Sustentável. Cadernos de Ciência e Tecnologia, Brasília, v.14, n.3, p.412-447. 1997.

HANAZAKI, N. Comunidades, conservação e manejo: o papel do conhecimento ecológico local. Biotemas, Florianópolis, v.16, n.1, p. 23-47. 2003.

INMET. Instituto Nacional de Meteorologia. Normais Climatológicas do Brasil 19611990. Disponível em www.inmet.gov.br. Acessado em 23 de out. 2011.

ISLAM, M. A.; AHMED, F.; DAS, A. K.; BACHAR, S. C. Analgesic and antiinflammatory activity of Leonurus sibiricus. Fitoterapia, Botucatu, v.76, n.3-4, p.359-362. 2005 .

LEITE, J. P. V.; FERNANDES, J. M.; FAVARO, L. B.; GONTIJO, D. C.; MAROTTA, C. P. B.; SIQUEIRA, L. C.; MAIA, R. T; GARCIA, F. C. P. MG Biota - Instituto Estadual de Florestas, v.1, n.4, p. 16-34. 2008.

LESSA, M. A.; ARAÚJO, C. V.; KAPLAN, M. A.; PIMENTA, D.; FIGUEIREDO, M. R.; TIBIRIÇÁ, E. Antihypertensive effects of crude extracts from leaves of Echinodorus grandiflorus. Fundamental \& Clinical Pharmacology, Saint-Étienne (França), v.22, n.2, p.161-168. 2008.

LIMA, T. C. D.; CARDOSO, M.V.; MODESTO, T.; OLIVEIRA, A. B. B.; SILVA, M. N.; MONTEIRO, M.C.. Breve revisão etnobotânica, fitoquímica e farmacologia de Stryphnodendron adstringens utilizada na Amazônia. Revista Fitos, Rio de Janeiro, S.l, v.10, n.3, p. 329-338. 2017.

LOPES, C.; RUCHKYS, U. Recursos da geodiversidade de São Thomé das Letras - MG e seu uso para mineração e geoconservação: perspectivas para a reconversão desse território mineiro. Desenvolvimento e Meio Ambiente, Curitiba, v. 35, p. 335-347. 2015. 
LOPES, R. M. F.; FREITAS, V. L. O.; BARBOSA, P. M. M. Estrutura do componente arbóreo em áreas de cerrado no município de São Tomé das Letras, MG. Revista Árvore, Viçosa, v.37. n. 5, p. 801-813. 2013.

MACIEL, M. A. M.; PINTO, A. C.; VEIGA, V. E. Plantas medicinais: a necessidade de estudos multidisciplinares. Química Nova, São Paulo, v.25, n, 23, p. 429-438. 2002.

MARQUES, M.; PROVANCE, JR. D. W.; KAPLAN, M.A.C.; FIGUEIREDO, M. R. Echinodorus grandiflorus: Ethnobotanical, phytochemical and pharmacological overview of a medicinal plant used in Brazil. Food and Chemical Toxicology, Reus (Spain), v.109, n.2, p.1032-1047, 2017.

MARTIN, G. J. Ethnobotany: a methods manual. London: Chapman \& Hall. 1995 268p.

MARTINS, E. R.; CASTRO, D. M.; CASTEllani, D. C.; DIAS, J. E. Plantas Medicinais. Viçosa, Editora UFV. 2000. 220p.

MUNARI, C. C.; OLIVEIRA, P. F.; CAMPOS, J. C. L.; MARTINS, S. P. L.; COSTA, J. C.; BASTOS, J. K.; TAVARES, D. C. Antiproliferative activity of Solanum lycocarpum alkaloidic extract and their constituents, solamargine and solasonine, in tumor cell lines. Journal of Natural Medicines, Chiba (Japan), v. 68, n.1, p.236-241. 2014.

NEWMAN, D. J.; CRAGG, G. M. J. Natural products as sources of new drugs over the 30 years from 1981 to 2010. Journal of Natural Products, New York, v.75, n.3, p.311-335. 2012.

OLIVEIRA-FILHO, T. A.; FLUMINHAN-FILHO, M. Ecologia da vegetação do Parque Florestal Quedas do Rio Bonito. Revista Cerne, Lavras, v. 5, n.2, p. 51-64. 1999.

ORGANIZAÇÃO MUNDIAL DA SAÚDE. CID - 10: Classificação Estatística Internacional de Doenças e Problemas Relacionados à Saúde. São Paulo, Editora da Universidade de São Paulo. 2000. 410p.

QUINTANS, L. J.; SANTANA, M. T.; MELO, M. S.; DE SOUSA, D. P.; SANTOS, I. S.; SIQUEIRA, R. S.; LIMA, T. C.; SILVEIRA, G. O.; ANTONIOLLI, A. R.; RIBEIRO, L. A. A.; SANTOS, M. R. V. Antinociceptive and anti-inflammatory effects of Costus spicatus in experimental animals. Pharmaceutical Biology, Massachusetts, v.48, n.10, p.1097-1102. 2010.

RABELO, A. C. S.; COSTA, D. C. A review of biological and pharmacological activities of Baccharis trimera. Chemico-Biological Interactions, Konstanz (Germany), v. 296, p.65-75. 2018.

RIBEIRO, J. F.; WALTER, B. M. T. As principais fitofisionomias do bioma Cerrado. In: SANO, S. M.; ALMEIDA, S. P.; RIBEIRO, J. F. (Ed.). Cerrado: Ecologia e flora. Brasília, DF: Embrapa Informação Tecnológica, v.1. p.153-212. 2008.

RODRIGUES, L. A.; CARVAlHO, D. A.; GOMES, L. J.; BOTREL, R. T. Espécies vegetais nativas usadas pela população local em Luminárias, MG. Boletim Técnico. Lavras, v.52, n.59 p. 1-54. 2002. 
RODRIGUES, V. E. G.; CARVALHO, D. A. Floristic of Native Medicinal Plants of Reminiscent Seasonal Semi-Deciduas Forest In The Alto Rio Grande Region - Minas Gerais. Cerne, Lavras, v. 14, n. 2, p. 93-112. 2015.

RODRIGUES, V. E. G.; CARVALHO, D. A. Florística de plantas medicinais nativas de remanescentes de floresta estacional semidecidual na região do Alto Rio Grande, Minas Gerais. Cerne, Lavras, v.14, n. 2, p. 93-112. 2008.

RODRIGUES, V. E. G.; CARVALHO, D. A. Levantamento etnobotânico de plantas medicinais no domínio dos cerrados na região do Alto Rio Grande, Minas Gerais. Ciência Agrotecnica, Lavras, v. 25, n.1, p. 102-123. 2001.

RODRIGUES, V. E. G.; CARVALHO, D. A. Plantas Medicinais Nativas nas Florestas Semideciduais. Lavras: UFLA, 2010. 128p.

RODRIGUeS, V. E. G.; CARVAlHO, D. A. Plantas Medicinais no Domínio dos Cerrados. Lavras: UFLA. 2001. 180 p.

ROSA, E. A.; SILVA, B. C.; SILVA, F. M.; TANAKA, C. M. A.; PERALTA, R. M.; OLIVEIRA, C. M. A.; KATO, L.; FERREIRA, H. D.; SILVA, C. C. Flavonóides e atividade antioxidante em Palicourea rigida Kunth, Rubiaceae. Revista Brasileira de Farmacognosia, Curitiba, v.20, n.4, p. 484-488, 2010.

RUPPELT, B. M.; PEREIRA, E. F. R.; GONCALVES, L. C.; PEREIRA, N. A. Pharmacological screening of plants recommended by folk medicine as anti-snake venom: I. Analgesic and anti-inflammatory activities. Memorial Instituto Oswaldo Cruz, Rio de Janeiro, v.86, n. 2, p.203-205. 1991.

SCHWARZ, A.; PINTO, E.; HARAGUCHI, M.; OLIVEIRA, C. A.; BERNARDI, M. M.; SOUZA, S. H. Phytochemical study of Solanum lycocarpum (St. Hil) unripe fruit and its effects on rat gestation. Phytotherapy Research, Naples (Italy), v.21, n.11, p.1025-1028. 2007.

SHIN, H. Y.; KIM, S. H.; KANG, S. M.; CHANG, I. J.; KIM, S.Y.; JEON, H.; LEEM, K. H.; PARK, W. H.; LIM, J. P; SHIN, T. Y. Anti-inflammatory activity of Motherwort (Leonurus sibiricus L.). Immunopharmacology and Immunotoxicology, v.31, n.2, p.209213. 2009.

SOUZA, U. J. B.; VITORINO, L. C, BESSA, L. A. Trends in the scientific literature on Stryphnodendron adstringens (Leguminosae): an important Brazilian medicinal tree. Multi-Science Journal, Uruta, v.3, n.1, p.8-15. 2020.

THIOLLENT, Michel. Metodologia da pesquisa-ação. 18. ed. São Paulo: Cortez. 2011. $136 \mathrm{p}$.

VIEIRA, G. JR.; FERREIRA, P. M.; MATOS, L. G.; FERREIRA, E. C.; RODOVALHO, W.; FERRI, P. H.; FERREIRA, H. D.; COSTA, E. A. Anti-inflammatory effect of Solanum lycocarpum fruits. Phytotherapy Research, Naples (Italy), v.17, n.8, p.892-896. 2003. 
FERREIRA-LOPES et al. Conhecimento popular de plantas medicinais no município de São Thomé das Letras, MG. Ethnoscientia v. 6, 2021. D.O.I.: 10.22276/ethnoscientia.v6i1.345.

WELLER, S. C.; KIMBALL-ROMNEY, A. Systematic data collection. Newbury: SAGE. 1988. $96 \mathrm{p}$. 
Apêndice 1. Relação das espécies de plantas medicinais conhecidas por informantes de São Thomé das Letras, MG, agrupadas por família botânica. Citações = número de informantes que citaram determinado uso para a espécie. As plantas com ** são de interesse do Sistema Único de Saúde (SUS) para estudos sobre produção de fitoterápicos.

\begin{tabular}{|c|c|c|c|c|c|c|}
\hline Nome científico & Nome popular & Hábito & Usos & Partes utilizadas & Modos de usar & Citações \\
\hline \multirow{4}{*}{\multicolumn{2}{|c|}{$\begin{array}{l}\text { Alismataceae } \\
\text { Echinodorus grandiflorus (Cham. \& } \\
\text { Schltdl.) Micheli }\end{array}$}} & \multirow{4}{*}{ arbustivo } & & & & \\
\hline & & & a. alergia, feridas na pele & a. folhas & a. açúcar raizeiro & a. 5 \\
\hline & & & b. infecção nos rins & b. folhas & b. infusão ou decocção, para beber & b.5 \\
\hline & & & $\begin{array}{l}\text { c. dor de estômago, boca } \\
\text { amarga }\end{array}$ & c. folhas & c. infusão ou decocção, para beber & c. 2 \\
\hline \multicolumn{7}{|l|}{ Amaranthaceae } \\
\hline Alternanthera brasiliana (L.) Kuntze & terramicina & herbáceo & infecção dos órgão internos & folhas & infusão, para beber & 3 \\
\hline \multicolumn{7}{|l|}{ Anacardiaceae } \\
\hline \multirow{2}{*}{ Anacardium humile A.St.-Hil. } & cajuzinho-do-campo & arbustivo & a. diabetes & a. planta inteira & a. decocção, para beber & a.1 \\
\hline & & & $\begin{array}{l}\text { b. inflamação no útero, cólica } \\
\text { menstrual }\end{array}$ & b. raízes & b. garrafada (vinho) para beber & b. 1 \\
\hline Annona crassiflora Mart. & araticum & arbóreo & Piolho & sementes & pó da semente torrada, nos cabelos & 1 \\
\hline \multicolumn{7}{|l|}{ Apiaceae } \\
\hline Eryngium pristis Cham. \& Schltdl. & goela-de-tucano & herbáceo & dor de dente & folhas & decocção, para gargarejo & 1 \\
\hline \multicolumn{7}{|l|}{ Apocynaceae } \\
\hline Aspidosperma sp. & guatambu & arbóreo & alergia na pele & raízes & infusão da raiz seca, para banho & 1 \\
\hline
\end{tabular}


Continuação do apêndice 1 .

\begin{tabular}{|c|c|c|c|c|c|c|}
\hline Nome científico & Nome popular & Hábito & \begin{tabular}{|l|} 
Usos \\
\end{tabular} & Partes utilizadas & Modos de usar & Citações \\
\hline \multicolumn{7}{|l|}{ Apocynaceae } \\
\hline Aspidosperma sp. & guatambu & arbóreo & alergia na pele & raízes & infusão da raiz seca, para banho & 1 \\
\hline \multicolumn{7}{|l|}{ Araliaceae } \\
\hline \multirow{2}{*}{$\begin{array}{l}\text { Didymopanax macrocarpus (Cham. \& } \\
\text { Schltdl.) Seem. }\end{array}$} & mandioquinha & arbóreo & a. feridas na pele, brotoejas & a. folhas & a. açúcar raizeiro & a. 4 \\
\hline & & & $\begin{array}{l}\text { b. infecção de garganta e } \\
\text { estômago }\end{array}$ & b. raízes & b. açúcar raizeiro & b. 1 \\
\hline \multicolumn{7}{|l|}{ Aristolochiaceae } \\
\hline Aristolochia sp. & buta-jarrinha & herbáceo & $\begin{array}{l}\text { dor de estômago, males do } \\
\text { fígado }\end{array}$ & planta inteira & $\begin{array}{l}\text { flores maceradas na água, para } \\
\text { beber; infusão de folhas secas no } \\
\text { café; mascar raiz }\end{array}$ & 6 \\
\hline \multicolumn{7}{|l|}{ Asteraceae } \\
\hline \multirow[t]{2}{*}{ Achyrocline satureioides (Lam.) DC. } & $\begin{array}{l}\text { macela, macela do } \\
\text { campo, macelinha }\end{array}$ & herbáceo & a. diarreia & a. folhas e flores & a. infusão, para beber & a. 4 \\
\hline & & & b. bronquite & b. folhas e flores & $\begin{array}{l}\text { b. ramos secos entre o travesseiro e } \\
\text { a fronha }\end{array}$ & b.4 \\
\hline \multirow[t]{3}{*}{ Achyrocline satureioides (Lam.) DC. } & & & c. calmante & c. folhas e flores & $\begin{array}{l}\text { c. ramos secos entre o travesseiro e a } \\
\text { fronha; flores maceradas na água, para } \\
\text { beber }\end{array}$ & c. 3 \\
\hline & & & d. problemas de visão & d. flores & $\begin{array}{l}\text { d. flores maceradas na água, para } \\
\text { banho }\end{array}$ & d. 1 \\
\hline & & & e. dor de ouvido & e. flores & $\begin{array}{l}\text { e. flores maceradas no azeite de } \\
\text { mamona, para pingar no ouvido }\end{array}$ & e.1 \\
\hline
\end{tabular}


FERREIRA-LOPES et al. Conhecimento popular de plantas medicinais no município de São Thomé das Letras, MG. Ethnoscientia v. 6, 2021. D.O.I.: 10.22276/ethnoscientia.v6i1.345.

Continuação do apêndice 1 .

\begin{tabular}{|c|c|c|c|c|c|c|}
\hline Nome científico & Nome popular & Hábito & Usos & Partes utilizadas & Modos de usar & Citações \\
\hline \multirow[t]{7}{*}{ Ageratum conyzoides $(\mathrm{L}.) \mathrm{L}}$. & $\begin{array}{l}\text { erva-de-são-joão, } \\
\text { mentruste, mentraste }\end{array}$ & herbáceo & a. cólica abdominal & a. planta inteira & a. decocção, para beber & a.3 \\
\hline & & & b. cólica pós-parto & b. planta inteira & $\begin{array}{l}\text { b. garrafada (cachaça) para beber; } \\
\text { infusão, para banho }\end{array}$ & b. 2 \\
\hline & & & c. gripe, tosse, peito cheio & c. planta inteira & c. xarope ou infusão, para beber & c. 3 \\
\hline & & & d. dor de estômago & d. folhas e flores & d. consumo na salada in natura & d. 1 \\
\hline & & & e. dor de ouvido & e. planta inteira & e. macerado, para pingar no ouvido & e.1 \\
\hline & & & $\begin{array}{l}\text { f. contusão dos órgãos } \\
\text { internos }\end{array}$ & f. planta inteira & $\begin{array}{l}\text { f. garrafada (álcool de cereais), } \\
\text { para beber e uso tópico }\end{array}$ & f. 1 \\
\hline & & & g. hemorroidas & g. raízes & g. decocção, para banho & g.1 \\
\hline \multirow[t]{6}{*}{ **Baccharis trimera (Less.) DC. } & carqueja & herbáceo & $\begin{array}{l}\text { a. colesterol alto, males do } \\
\text { fígado }\end{array}$ & a. folhas & $\begin{array}{l}\text { a. folhas maceradas na água, para } \\
\text { beber }\end{array}$ & a.6 \\
\hline & & & b. diabetes & b. folhas & $\begin{array}{l}\text { b. folhas maceradas na água, para } \\
\text { beber; garrafada (cachaça), para } \\
\text { beber }\end{array}$ & b. 2 \\
\hline & & & c. caspa, piolho & c. folhas & $\begin{array}{l}\text { c. folhas maceradas na água, para } \\
\text { banho }\end{array}$ & c. 2 \\
\hline & & & d. reumatismo & d. folhas & $\begin{array}{l}\text { d. folhas maceradas na água, para } \\
\text { banho }\end{array}$ & d.1 \\
\hline & & & $\begin{array}{l}\text { e. limpeza de pele, herpes, } \\
\text { verme, dor de cabeça }\end{array}$ & e. folhas & e. açúcar raizeiro & e. 1 \\
\hline & & & f. pós-parto de vaca & f. folhas & $\begin{array}{l}\text { f. folhas maceradas em água com } \\
\text { fubá e sal, para a vaca beber }\end{array}$ & f.1 \\
\hline
\end{tabular}


FERREIRA-LOPES et al. Conhecimento popular de plantas medicinais no município de São Thomé das Letras, MG. Ethnoscientia v. 6, 2021. D.O.I.: 10.22276/ethnoscientia.v6i1.345.

Continuação do apêndice 1 .

\begin{tabular}{|c|c|c|c|c|c|c|}
\hline Nome científico & Nome popular & Hábito & Usos & Partes utilizadas & Modos de usar & Citações \\
\hline \multirow{3}{*}{ Baccharis dracunculifolia DC. } & alecrim-vassoura & arbustivo & a. gripe, resfriado, bronquite & a. folhas & a. infusão, para beber & a.3 \\
\hline & & & b. carrapato & b. folhas & b. bater galhos na roupa & b. 1 \\
\hline & & & c. curar umbigo & c. folhas & $\begin{array}{l}\text { c. pó das folhas secas sobre } \\
\text { umbigo }\end{array}$ & c. 1 \\
\hline \multirow[t]{2}{*}{ Bidens brasiliensis Sherff } & $\begin{array}{l}\text { picão-cipó - beira de } \\
\text { rio }\end{array}$ & liana & $\begin{array}{l}\text { a. infecção dos órgãos } \\
\text { internos }\end{array}$ & a. folhas & a. infusão ou decocção, para beber & a. 2 \\
\hline & & & b. tuberculose, gripe, tosse & b. cipó & b. infusão ou decocção, para beber & b. 1 \\
\hline \multirow[t]{9}{*}{ Bidens pilosa $\mathrm{L}$. } & picão & herbáceo & a. icterícia & a. planta inteira & $\begin{array}{l}\text { a. decocção, para beber e para } \\
\text { banho }\end{array}$ & a.4 \\
\hline & & & b. dor de estômago e fígado / & & & \\
\hline & & & inchaço nas pernas & & & \\
\hline & & & muscular, machucados, banho & & & \\
\hline & & & $\begin{array}{l}\text { de assento / hemorroida / } \\
\text { fígado e rim (infecção de } \\
\text { urina) / Inflamações, infecção } \\
\text { de urina, intestino, etc. }\end{array}$ & b. planta inteira & b. decocção, para banho & b.1 \\
\hline & & & c. hemorroida & c. planta inteira & c. decocção, para vaporização anal & c. 1 \\
\hline & & & d. infecção dos órgão internos & d. planta inteira & d. decocção, para beber & d.1 \\
\hline & & & e. pressão alta & e. raízes & e. decocção, para beber & e. 1 \\
\hline & & & $\begin{array}{l}\text { f. dor de dente, de cabeça e } \\
\text { de ouvido }\end{array}$ & f. raízes & f. decocção, para beber & f.1 \\
\hline
\end{tabular}


FERREIRA-LOPES et al. Conhecimento popular de plantas medicinais no município de São Thomé das Letras, MG. Ethnoscientia v. 6, 2021. D.O.I.: 10.22276/ethnoscientia.v6i1.345.

Continuação do apêndice 1 .

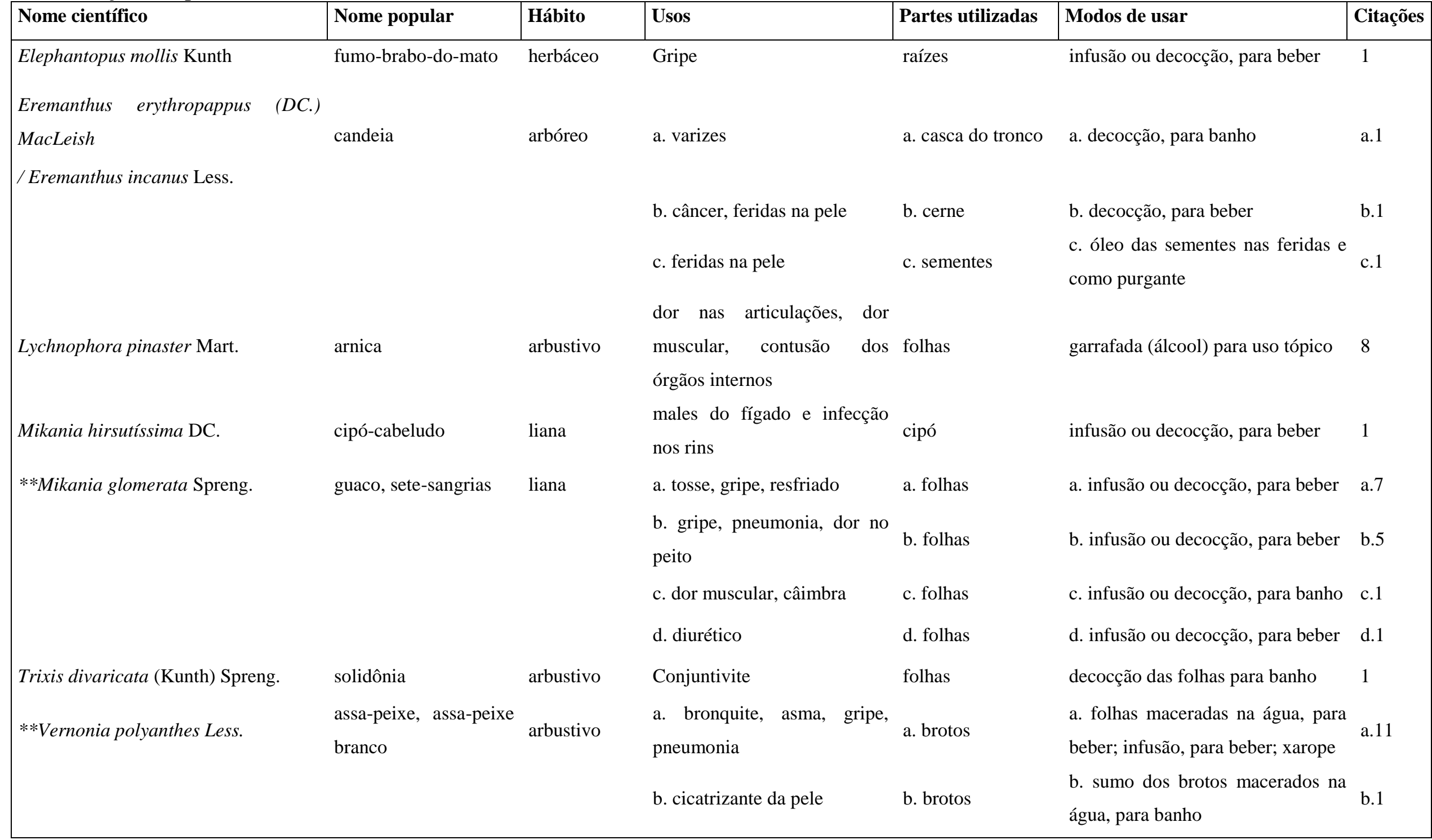


FERREIRA-LOPES et al. Conhecimento popular de plantas medicinais no município de São Thomé das Letras, MG. Ethnoscientia v. 6, 2021. D.O.I.: 10.22276/ethnoscientia.v6i1.345.

Continuação do apêndice 1 .

\begin{tabular}{|c|c|c|c|c|c|c|}
\hline Nome científico & Nome popular & Hábito & Usos & Partes utilizadas & Modos de usar & Citações \\
\hline \multirow[t]{2}{*}{ Vernonia sp. } & \multirow[t]{2}{*}{ assa-peixe roxo } & \multirow[t]{2}{*}{ arbustivo } & a. dor nas costas & a. brotos & $\begin{array}{l}\text { a. sumo dos brotos macerados na } \\
\text { água, para banho }\end{array}$ & a. 1 \\
\hline & & & $\begin{array}{l}\text { b. depurativo do sangue, } \\
\text { limpeza de pele }\end{array}$ & b. brotos & b. açúcar raizeiro & b.1 \\
\hline \multicolumn{7}{|l|}{ Bignoniaceae } \\
\hline \multirow[t]{3}{*}{ Jacaranda decurrens Cham. } & \multirow[t]{3}{*}{ carobinha } & \multirow[t]{3}{*}{ arbustivo } & $\begin{array}{l}\text { a. depurativo do sangue, } \\
\text { alergia na pele }\end{array}$ & a. raízes & a. açúcar raizeiro & a.9 \\
\hline & & & b. pedra nos rins & b. folhas & b. infusão ou decocção, para beber & b. 2 \\
\hline & & & c. alcoolismo & c. raízes & $\begin{array}{l}\text { c. garrafada (vinho moscatel ou } \\
\text { branco), para beber }\end{array}$ & c. 1 \\
\hline Jacaranda puberula Cham. & $\begin{array}{l}\text { caroba-de-folha- } \\
\text { grande }\end{array}$ & arbóreo & $\begin{array}{l}\text { depurativo do sangue, } \\
\text { limpeza de pele }\end{array}$ & Folhas & açúcar raizeiro & 1 \\
\hline \multirow[t]{2}{*}{ Pyrostegia venusta (Ker Gawl.) Miers } & cipó-de-são-joão & liana & a. dor de cabeça & a. flores & a. infusão ou decocção, para beber & a. 2 \\
\hline & & & $\begin{array}{l}\text { b. dor na coluna, dor nas } \\
\text { pernas }\end{array}$ & b. folhas e flores & b. infusão ou decocção, para beber & b.1 \\
\hline \multicolumn{7}{|l|}{ Bromeliaceae } \\
\hline Bromelia sp. & gravatá & arbustivo & $\begin{array}{l}\text { bronquite, asma, dor de } \\
\text { estômago }\end{array}$ & folhas & $\begin{array}{l}\text { decocção das folhas pra beber, } \\
\text { frutos para ingestão in natura }\end{array}$ & 1 \\
\hline
\end{tabular}


Continuação do apêndice 1 .

\begin{tabular}{|c|c|c|c|c|c|c|}
\hline Nome científico & Nome popular & Hábito & Usos & Partes utilizadas & Modos de usar & Citações \\
\hline \multicolumn{7}{|l|}{ Caryocaraceae } \\
\hline Caryocar brasiliense A.St.-Hil. & pequi & arbóreo & Anemia & sementes & ingestão do arilo cozido & 1 \\
\hline \multicolumn{7}{|l|}{ Cecropiaceae } \\
\hline \multirow[t]{3}{*}{ Cecropia sp. } & \multirow[t]{3}{*}{ embaúba } & \multirow[t]{3}{*}{ arbóreo } & a. bronquite, tosse, gripe & a. folhas e frutos & a. xarope; decocção, para beber & a.3 \\
\hline & & & b. dor nas articulações & b. folhas & b. decocção, para banho & b. 1 \\
\hline & & & c. ferimentos na pele & c. folhas & c. decocção, para banho & c. 1 \\
\hline \multicolumn{7}{|l|}{ Celastraceae } \\
\hline \multirow[t]{3}{*}{ **Maytenus aquifolium Mart. } & \multirow[t]{3}{*}{$\begin{array}{l}\text { espinheira-santa, } \\
\text { espinheira-de-folha }\end{array}$} & \multirow[t]{3}{*}{ arbóreo } & $\begin{array}{l}\text { a. pós-parto, úlcera, males do } \\
\text { fígado, pedra nos rins }\end{array}$ & a. folhas & a. garrafada (cachaça), para beber & a.7 \\
\hline & & & b. cicatrizante da pele & b. folhas & b. açúcar raizeiro & b.1 \\
\hline & & & $\begin{array}{l}\text { b. infecção dos órgãos } \\
\text { internos }\end{array}$ & b. folhas & b. infusão ou decocção, para beber & b.1 \\
\hline \multicolumn{7}{|l|}{ Chenopodiaceae } \\
\hline \multirow[t]{3}{*}{ **Chenopodium ambrosioides L. } & \multirow[t]{3}{*}{ erva-de-santa-maria } & \multirow[t]{3}{*}{ herbáceo } & a. vermes & a. raízes & a. garrafada (vinho ou leite) & a.3 \\
\hline & & & b. gripe, pneumonia & b. folhas & b. infusão, para beber & b.1 \\
\hline & & & c. pulgas & c. folhas & c. ramos embaixo do colchão & c. 1 \\
\hline \multicolumn{7}{|l|}{ Convolvulaceae } \\
\hline Cuscuta racemosa Mart. & cipó-chumbo & liana & pedra nos rins & cipó & decocção, para beber & 1 \\
\hline
\end{tabular}


FERREIRA-LOPES et al. Conhecimento popular de plantas medicinais no município de São Thomé das Letras, MG. Ethnoscientia v. 6, 2021. D.O.I.: 10.22276/ethnoscientia.v6i1.345.

Continuação do apêndice 1 .

\begin{tabular}{|c|c|c|c|c|c|c|}
\hline Nome científico & Nome popular & Hábito & Usos & Partes utilizadas & Modos de usar & Citações \\
\hline \multirow[t]{2}{*}{ Merremia tomentosa Hallier } & $\begin{array}{l}\text { velame-do-campo, } \\
\text { velame-do-cupim, } \\
\text { rabo-de-tatu }\end{array}$ & herbáceo & a. alergia na pele & a. raízes & a. açúcar raizeiro & a. 6 \\
\hline & & & $\begin{array}{l}\text { b. depurativo do sangue, } \\
\text { feridas na pele }\end{array}$ & b. raízes & b. açúcar raizeiro & b. 1 \\
\hline \multicolumn{7}{|l|}{ Dilleniaceae } \\
\hline \multirow[t]{2}{*}{ Davilla rugosa Poir. } & cipó-caboclo & liana & $\begin{array}{l}\text { a. varizes, dor na perna, } \\
\text { queda de cabelo }\end{array}$ & a. cipó & a. decocção, para banho & a. 1 \\
\hline & & & b. hemorroidas & b. cipó & b. decocção, para banho & b. 1 \\
\hline \multicolumn{7}{|l|}{ Erythroxyllaceae } \\
\hline Erythroxylum tortuosum Mart. & cabeça-de-negro & arbustivo & $\begin{array}{l}\text { estimulante sexual masculino } \\
\text { e feminino }\end{array}$ & Folhas & infusão ou decocção, para beber & 1 \\
\hline \multicolumn{7}{|l|}{ Euphorbiaceae } \\
\hline \multirow[t]{4}{*}{ Croton antisyphiliticus Mart. } & $\begin{array}{l}\text { curraleira, erva-de- } \\
\text { perdiz }\end{array}$ & herbáceo & a. alergia, feridas na pele & a. folhas & a. açúcar raizeiro & a.11 \\
\hline & & & $\begin{array}{l}\text { b. banho de assento de pós- } \\
\text { parto, corrimento vaginal }\end{array}$ & b. folhas & b. decocção, para banho & b. 3 \\
\hline & & & c. pedra nos rins & c. folhas & c. decocção, para beber & c. 1 \\
\hline & & & d. tuberculose & d. folhas & d. suco, para beber & d.1 \\
\hline
\end{tabular}


FERREIRA-LOPES et al. Conhecimento popular de plantas medicinais no município de São Thomé das Letras, MG. Ethnoscientia v. 6, 2021. D.O.I.: 10.22276/ethnoscientia.v6i1.345.

Continuação do apêndice 1 .

\begin{tabular}{|c|c|c|c|c|c|c|}
\hline Nome científico & Nome popular & Hábito & Usos & Partes utilizadas & Modos de usar & Citações \\
\hline \multicolumn{7}{|l|}{ Fabaceae } \\
\hline Acacia tenuifolia (L.) Willd. & arranha-gato & arbustivo & $\begin{array}{l}\text { anti-inflamatório, cicatrizante } \\
\text { da pele }\end{array}$ & $\begin{array}{l}\text { folhas, } \\
\text { frutos }\end{array}$ & decocção, para banho & 1 \\
\hline \multirow[t]{3}{*}{ Bauhinia sp.1 } & cipó-cobra & liana & $\begin{array}{l}\text { a. dor de dente, infecção na } \\
\text { gengiva }\end{array}$ & a. cipó & $\begin{array}{l}\text { a. decocção, para beber ou } \\
\text { gargarejar }\end{array}$ & a. 4 \\
\hline & & & $\begin{array}{l}\text { b. diabetes, infecção nos rins, } \\
\text { males do fígado }\end{array}$ & b. cipó & b. decocção, para beber & b. 2 \\
\hline & & & c. mordida de cobra & c. cipó & c. decocção, para banho & c. 1 \\
\hline \multirow[t]{2}{*}{ Bauhinia sp.2 } & $\begin{array}{l}\text { pata-de-vaca, unha-de- } \\
\text { vaca }\end{array}$ & arbóreo & a. diabetes & a. folhas & a. infusão ou decocção, para beber & a.5 \\
\hline & & & b. falta de ar & b. folhas & b. infusão ou decocção, para beber & b. 1 \\
\hline Clitoria guyanensis (Aubl.) Standl. & catuaba & herbáceo & $\begin{array}{l}\text { estimulante sexual, infecção } \\
\text { nos rins, males do fígado }\end{array}$ & raízes & garrafada (vinho), para beber & 1 \\
\hline **Copaifera langsdorffii Desf. & óleo-de-copaíba & arbóreo & $\begin{array}{l}\text { a. bronquite, pneumonia, dor } \\
\text { no peito e nas costas }\end{array}$ & a. resina & $\begin{array}{l}\text { a. gotas de resina na água, para } \\
\text { banho }\end{array}$ & a.3 \\
\hline \multirow{3}{*}{ Desmodium sp. } & & & $\begin{array}{l}\text { b. candidíase e dor de barriga } \\
\text { em bezerros }\end{array}$ & b. resina & $\begin{array}{l}\text { b. gotas de resina na água, para } \\
\text { beber }\end{array}$ & b. 1 \\
\hline & $\begin{array}{l}\text { prega-prega, amor- } \\
\text { seco, carrapichinho }\end{array}$ & herbáceo & a. pedra nos rins & a. planta inteira & a. infusão ou decocção, para beber & a. 4 \\
\hline & & & b. diabetes & b. planta inteira & b. infusão ou decocção, para beber & b. 1 \\
\hline
\end{tabular}


Continuação do apêndice 1 .

\begin{tabular}{|c|c|c|c|c|c|c|}
\hline Nome científico & Nome popular & Hábito & Usos & Partes utilizadas & Modos de usar & Citações \\
\hline \multirow[t]{4}{*}{ Erythrina falcata Benth. } & $\begin{array}{l}\text { muxoco, lagoa- } \\
\text { dourada, suliman }\end{array}$ & arbóreo & $\begin{array}{l}\text { a. depurativo do sangue, } \\
\text { feridas na pele }\end{array}$ & a. casca do tronco & a. açúcar raizeiro & a. 5 \\
\hline & & & $\begin{array}{l}\text { b. cicatrizante da pele, } \\
\text { pisadura de cavalo }\end{array}$ & b. folhas & b. decocção, para banho & b. 2 \\
\hline & & & c. alcoolismo & c. raízes & $\begin{array}{l}\text { c. garrafada (vinho moscatel ou } \\
\text { branco), para beber }\end{array}$ & c. 2 \\
\hline & & & d. corrimento vaginal & d. casca do tronco & d. decocção, para banho & d.1 \\
\hline \multirow[t]{3}{*}{$\begin{array}{l}\text { Hymenaea stigonocarpa Hayne } \\
\text { Hymenaea courbaril L. }\end{array}$} & jatobá & arbóreo & a. males de próstata, verme & a. frutos & $\begin{array}{l}\text { a. xarope com a casca do fruto } \\
\text { torrada }\end{array}$ & a.7 \\
\hline & & & b. resfriado e gripe com tosse & b. frutos & $\begin{array}{l}\text { b. infusão da casca do fruto } \\
\text { torrada, para beber }\end{array}$ & b.5 \\
\hline & & & c. verme, solitária & c. frutos & $\begin{array}{l}\text { c. xarope com a casca do fruto } \\
\text { torrada }\end{array}$ & c. 1 \\
\hline \multirow[t]{3}{*}{$\begin{array}{l}\text { Senna cathartica (L.) HS. Irwin \& } \\
\text { Barneby }\end{array}$} & sene, sene-do-campo & arbustivo & a. purgante & a. folhas & a. infusão ou decocção, para beber & a.2 \\
\hline & & & b. gripe & b. folhas & b. infusão ou decocção, para beber & b. 2 \\
\hline & & & c. cicatrizante interno & c. folhas & c. infusão ou decocção, para beber & c. 1 \\
\hline \multirow[t]{2}{*}{$\begin{array}{l}\text { **Stryphnodendron } \\
\text { (Mart.) Coville }\end{array}$} & barbatimão & arbóreo & $\begin{array}{l}\text { a. cicatrizante da pele, anti- } \\
\text { inflamatório (banhos pós- } \\
\text { parto) }\end{array}$ & a. casca do tronco & $\begin{array}{l}\text { a. casca torrada sobre ferimentos } \\
\text { da pele }\end{array}$ & a.17 \\
\hline & & & $\begin{array}{l}\text { b. cicatrizante da pele e } \\
\text { abortivo }\end{array}$ & b. casca do tronco & b. casca na água, para banho & b.1 \\
\hline
\end{tabular}


Continuação do apêndice 1 .

\begin{tabular}{|c|c|c|c|c|c|c|}
\hline Nome científico & Nome popular & Hábito & Usos & Partes utilizadas & Modos de usar & Citações \\
\hline \multicolumn{7}{|l|}{ Lamiaceae } \\
\hline Keithia denudata Benth. & poejo-do-campo & herbáceo & Gripe & flores & infusão ou decocção, para beber & 1 \\
\hline \multirow[t]{2}{*}{ Leonurus sibiricus L. } & isopo, isope & herbáceo & $\begin{array}{l}\text { a. tosse, gripe, pneumonia, } \\
\text { bronquite, dor de cabeça }\end{array}$ & a. raízes & a. raízes no xarope & a.11 \\
\hline & \multirow{5}{*}{ hortelã-do-campo } & \multirow{5}{*}{ herbáceo } & b. verme & b. planta inteira & b. garrafada (vinho), para beber & b. 1 \\
\hline \multirow{4}{*}{ Peltodon tomentosus Pohl } & & & $\begin{array}{l}\text { a. tosse, gripe, resfriado, } \\
\text { bronquite }\end{array}$ & a. folhas & a. infusão ou decocção, para beber & a.3 \\
\hline & & & b. alergia na pele & b. folhas & b. infusão ou decocção, para banho & b. 2 \\
\hline & & & c. cólica abdominal, vômito & c. folhas & c. infusão ou decocção, para beber & c. 1 \\
\hline & & & d. infecção nos rins & d. folhas & d. infusão ou decocção, para beber & d.1 \\
\hline \multicolumn{7}{|l|}{ Lauraceae } \\
\hline Ocotea odorifera (Vell.) Rohwer & sassafrás & arbóreo & Pneumonia & casca do tronco & garrafada (cachaça), para beber & 1 \\
\hline \multicolumn{7}{|l|}{ Liliaceae } \\
\hline Herreria salsaparrilha Mart. & salsaparilha & liana & problemas de pele & raízes & açúcar raizeiro & 5 \\
\hline \multicolumn{7}{|l|}{ Loganiaceae } \\
\hline \multirow[t]{2}{*}{ Strychnos brasiliensis (Spreng.) Mart. } & $\begin{array}{l}\text { quina-cruzeiro, } \\
\text { vermelhão }\end{array}$ & arbóreo & a. caspa, queda de cabelo & a. folhas & a. infusão ou decocção, para banho & a. 2 \\
\hline & & & $\begin{array}{l}\text { b. dor no estômago, ressaca } \\
\text { de bebida }\end{array}$ & b. casca do tronco & $\begin{array}{l}\text { b. casca do tronco na água, para } \\
\text { beber }\end{array}$ & b. 1 \\
\hline
\end{tabular}


FERREIRA-LOPES et al. Conhecimento popular de plantas medicinais no município de São Thomé das Letras, MG. Ethnoscientia v. 6, 2021. D.O.I.: 10.22276/ethnoscientia.v6i1.345.

Continuação do apêndice 1 .

\begin{tabular}{|c|c|c|c|c|c|c|}
\hline Nome científico & Nome popular & Hábito & Usos & Partes utilizadas & Modos de usar & Citações \\
\hline \multicolumn{7}{|l|}{ Malpighiaceae } \\
\hline \multirow[t]{3}{*}{ Banisteriopsis sp. } & cipó-prata & liana & a. infecção nos rins & a. folhas & a. infusão ou decocção, para beber & a.1 \\
\hline & & & b. bronquite, dor de garganta & b. folhas & b. infusão ou decocção, para beber & b. 1 \\
\hline & & & c. dor no estômago & c. folhas & c. infusão ou decocção, para beber & c. 1 \\
\hline \multicolumn{7}{|l|}{ Malpighiaceae } \\
\hline \multirow[t]{6}{*}{ Heteropterys anceps Nied. } & $\begin{array}{l}\text { suma-branca, guiné- } \\
\text { do-campo }\end{array}$ & herbáceo & a. problemas de pele, tumor & a. raízes & a. açúcar raizeiro & a.7 \\
\hline & & & $\begin{array}{l}\text { b. males do fígado e infecção } \\
\text { nos rins }\end{array}$ & b. raízes & b. decocção, para beber & b. 2 \\
\hline & & & c. alcoolismo & c. raízes & $\begin{array}{l}\text { c. garrafada (vinho moscatel ou } \\
\text { branco), para beber }\end{array}$ & c. 1 \\
\hline & & & $\begin{array}{l}\text { d. corrimento vaginal e } \\
\text { peniano }\end{array}$ & d. raízes & d. decocção, para banho & d.1 \\
\hline & & & $\begin{array}{l}\text { e. depurativo do sangue, } \\
\text { feridas na pele }\end{array}$ & e. planta inteira & e. açúcar raizeiro & e.1 \\
\hline & & & f. dor de dente & f. raízes & $\begin{array}{l}\text { f. infusão ou decocção, para } \\
\text { aplicar no dente }\end{array}$ & f.1 \\
\hline \multicolumn{7}{|l|}{ Malvaceae } \\
\hline Luehea sp. & açoita-cavalo & arbóreo & $\begin{array}{l}\text { males do fígado, depurativo } \\
\text { do sangue }\end{array}$ & folhas & infusão ou decocção, para beber & 2 \\
\hline
\end{tabular}


Continuação do apêndice 1 .

\begin{tabular}{|c|c|c|c|c|c|c|}
\hline Nome científico & Nome popular & Hábito & Usos & Partes utilizadas & Modos de usar & Citações \\
\hline \multicolumn{7}{|l|}{ Monimiaceae } \\
\hline Siparuna guianensis Aubl. & negamina & arbóreo & $\begin{array}{l}\text { inchaço nas pernas, dor } \\
\text { muscular, ferimentos na pele }\end{array}$ & folhas & infusão ou decocção, para banho & 5 \\
\hline \multicolumn{7}{|l|}{ Moraceae } \\
\hline \multirow[t]{2}{*}{ Brosimum gaudichaudii Trécul } & \multirow[t]{2}{*}{ manacá-do-campo } & \multirow[t]{2}{*}{ arbóreo } & $\begin{array}{l}\text { a. depurativo do sangue, } \\
\text { limpeza de pele }\end{array}$ & a. raízes & a. açúcar raizeiro & a. 2 \\
\hline & & & b. alcoolismo & b. raízes & $\begin{array}{l}\text { b. garrafada (vinho moscatel ou } \\
\text { branco), para beber }\end{array}$ & b. 1 \\
\hline Dorstenia brasiliensis Lam. & carapiá-do-mato & herbáceo & dor de dente, gripe & raízes & $\begin{array}{l}\text { fumar a raiz seca picada, a fumaça } \\
\text { cura resfriado }\end{array}$ & 8 \\
\hline \multicolumn{7}{|l|}{ Oxalidaceae } \\
\hline Oxalis sp. & azedinha (flor rosa) & herbáceo & feridas na boca & folhas & infusão, para beber ou bochechar & 1 \\
\hline \multicolumn{7}{|l|}{ Passifloraceae } \\
\hline Passiflora sp. & $\begin{array}{l}\text { maracujazinho-do- } \\
\text { mato }\end{array}$ & liana & pressão alta, insônia & folhas & $\begin{array}{l}\text { infusão ou decocção, para beber; } \\
\text { suco da polpa do fruto, para ingerir }\end{array}$ & 2 \\
\hline \multicolumn{7}{|l|}{ Phyllanthaceae } \\
\hline Phyllantus sp. & quebra-pedra & herbáceo & pedra nos rins & folhas & $\begin{array}{l}\text { folhas maceradas na água, para } \\
\text { beber }\end{array}$ & 4 \\
\hline \multicolumn{7}{|l|}{ Piperaceae } \\
\hline Piper aduncum $\mathrm{L}$. & jaborandi & arbustivo & cabelos enfraquecidos & folhas & $\begin{array}{l}\text { folhas maceradas na água, para } \\
\text { banho }\end{array}$ & 1 \\
\hline
\end{tabular}


FERREIRA-LOPES et al. Conhecimento popular de plantas medicinais no município de São Thomé das Letras, MG. Ethnoscientia v. 6, 2021. D.O.I.: 10.22276/ethnoscientia.v6i1.345.

Continuação do apêndice 1 .

\begin{tabular}{|c|c|c|c|c|c|c|}
\hline Nome científico & Nome popular & Hábito & Usos & Partes utilizadas & Modos de usar & Citações \\
\hline \multicolumn{7}{|l|}{ Polygalaceae } \\
\hline \multirow[t]{2}{*}{$\begin{array}{l}\text { Bredemeyera laurifolia Klotzsch ex } \\
\text { A.W.Benn. }\end{array}$} & \multirow[t]{2}{*}{ joão-da-costa, puteiro } & \multirow[t]{2}{*}{ herbáceo } & \multirow[t]{2}{*}{$\begin{array}{l}\text { a. infertilidade masculina e } \\
\text { feminina }\end{array}$} & a. raízes & \multicolumn{2}{|c|}{$\begin{array}{l}\text { a. garrafada (vinho branco) das } \\
\text { raízes raspadas da planta } \\
\text { masculina (para mulheres) e a.5 } \\
\text { feminina (para homens), com noz } \\
\text { moscada }\end{array}$} \\
\hline & & & & b. raízes & b. açúcar raizeiro & b. 1 \\
\hline \multirow[t]{2}{*}{ Polygala paniculata $\mathrm{L}$. } & \multirow[t]{2}{*}{ gelolzinho } & \multirow[t]{2}{*}{ herbáceo } & a. dor muscular & a. raízes & $\begin{array}{l}\text { a. garrafada (álcool) para uso } \\
\text { tópico }\end{array}$ & a. 2 \\
\hline & & & b. gripe & b. raízes & b. decocção, para beber & b. 1 \\
\hline \multicolumn{7}{|l|}{ Primulaceae } \\
\hline \multirow[t]{2}{*}{ Myrsine guianensis (Aubl.) Kuntze } & \multirow[t]{2}{*}{ capororoca } & \multirow[t]{2}{*}{ arbóreo } & a. estimulante sexual & a. folhas & a. infusão ou decocção, para beber & a.1 \\
\hline & & & $\begin{array}{l}\text { b. corrimento vaginal e } \\
\text { peniano }\end{array}$ & b. raízes & $\begin{array}{l}\text { b. infusão ou decocção, para beber } \\
\text { e banho }\end{array}$ & b. 1 \\
\hline \multicolumn{7}{|l|}{ Rosaceae } \\
\hline Rubus brasiliensis Mart. & $\begin{array}{l}\text { amora-branca, amora- } \\
\text { do-mato }\end{array}$ & arbustivo & $\begin{array}{l}\text { depurativo do sangue, feridas } \\
\text { na pele }\end{array}$ & folhas e raízes & $\begin{array}{l}\text { açúcar raizeiro*, infusão para } \\
\text { beber }\end{array}$ & 1 \\
\hline
\end{tabular}


FERREIRA-LOPES et al. Conhecimento popular de plantas medicinais no município de São Thomé das Letras, MG. Ethnoscientia v. 6, 2021. D.O.I.: 10.22276/ethnoscientia.v6i1.345.

Continuação do apêndice 1 .

\begin{tabular}{|c|c|c|c|c|c|c|}
\hline Nome científico & Nome popular & Hábito & Usos & Partes utilizadas & Modos de usar & Citações \\
\hline \multicolumn{7}{|l|}{ Rubiaceae } \\
\hline $\begin{array}{l}\text { Guettarda viburnoides Cham. \& } \\
\text { Schltdl. }\end{array}$ & veludo-do-mato & arbóreo & pedra nos rins & raízes & decocção, para beber & 1 \\
\hline \multirow[t]{4}{*}{ Palicourea rigida Kunth } & $\begin{array}{l}\text { douradinha, congonha, } \\
\text { congonha amarela }\end{array}$ & arbustivo & a. gripe & a. folhas & a. infusão ou decocção, para beber & a.1 \\
\hline & & & b. infecção nos rins & b. folhas & b. infusão ou decocção, para beber & b. 1 \\
\hline & & & c. dor no estômago & c. folhas & c. infusão ou decocção, para beber & c. 1 \\
\hline & & & d. queda de cabelo & d. folhas & d. infusão ou decocção, para banho & d.1 \\
\hline \multirow[t]{3}{*}{ Psychotria coccinea Poit. ex DC. } & roxinho & herbáceo & $\begin{array}{l}\text { a. dor no corpo, vísceras e } \\
\text { muscular }\end{array}$ & a. folhas & $\begin{array}{l}\text { a. infusão, para beber ou para } \\
\text { banho }\end{array}$ & a.3 \\
\hline & & & $\begin{array}{l}\text { b. dor de cabeça, dor de } \\
\text { estômago }\end{array}$ & b. folhas & b. infusão, para beber & b. 1 \\
\hline & & & c. artrose, artrite, tendinite & c. folhas & c. infusão, para banho & c. 1 \\
\hline \multirow[t]{2}{*}{ Rudgea viburnoides (Cham.) Benth. } & $\begin{array}{l}\text { douradinha-do-mato, } \\
\text { douradinha, congonha- } \\
\text { de-bugre, congonha- } \\
\text { de-índio }\end{array}$ & arbustivo & a. diurética, pedra nos rins & a. folhas & a. infusão ou decocção, para beber & a.10 \\
\hline & & & $\begin{array}{l}\text { b. depurativo do sangue, } \\
\text { alergia na pele }\end{array}$ & b. folhas & b. açúcar raizeiro & b. 2 \\
\hline
\end{tabular}


Continuação do apêndice 1 .

\begin{tabular}{|c|c|c|c|c|c|c|}
\hline Nome científico & Nome popular & Hábito & Usos & Partes utilizadas & Modos de usar & Citações \\
\hline \multicolumn{7}{|l|}{ Salicaceae } \\
\hline \multirow[t]{2}{*}{ **Casearia sylvestris $\mathrm{Sw}$. } & $\begin{array}{l}\text { erva-de-lagarto, } \\
\text { língua-de-tiú }\end{array}$ & \multirow[t]{2}{*}{ herbáceo } & a. infecção em peito de vaca & a. folhas & a. garrafada (álcool), para banho & a.1 \\
\hline & & & b. hemorroidas & b. folhas e raízes & b. vaporização anal & b. 1 \\
\hline \multicolumn{7}{|l|}{ Sapindaceae } \\
\hline \multirow[t]{3}{*}{ Cupania vernalis Cambess. } & \multirow[t]{3}{*}{ camboatá } & \multirow[t]{3}{*}{ arbóreo } & a. dor de cabeça & a. raízes & \multirow{3}{*}{$\begin{array}{l}\text { a. infusão ou decocção, para beber } \\
\text { b. folhas quentes em contato direto } \\
\text { com o peito da criança } \\
\text { c. folhas sapecadas no fogo, } \\
\text { trituradas, adicionadas ao azeite de } \\
\text { mamona, para passar na pele }\end{array}$} & a.1 \\
\hline & & & b. bronquite & b. folhas & & b.1 \\
\hline & & & $\begin{array}{l}\text { c. feridas, furúnculos, } \\
\text { queimaduras na pele, gripe }\end{array}$ & c. folhas & & c. 1 \\
\hline \multicolumn{7}{|l|}{ Smilacaceae } \\
\hline \multirow[t]{4}{*}{$\begin{array}{l}\text { Smilax cissoides M.Martens } \\
\text { Galeotti }\end{array}$} & $\stackrel{ }{\&}$ japecanga & liana & $\begin{array}{l}\text { a. alergias na pele, herpes, } \\
\text { verme }\end{array}$ & a. raízes & a. açúcar raizeiro & a.5 \\
\hline & & & b. verme & b. raízes & b. açúcar raizeiro & b.1 \\
\hline & & & c. dor de cabeça & c. raízes & c. açúcar raizeiro & c. 1 \\
\hline & & & d. bronquite & d. folhas e raízes & d. decocção, para beber & d.1 \\
\hline
\end{tabular}


Continuação do apêndice 1 .

\begin{tabular}{|c|c|c|c|c|c|c|}
\hline Nome científico & Nome popular & Hábito & Usos & Partes utilizadas & Modos de usar & Citações \\
\hline \multicolumn{7}{|l|}{ Solanaceae } \\
\hline \multirow[t]{3}{*}{ Solanum aculeatissimum Jacq. } & juá, juá-poca & herbáceo & a. furúnculo & a. frutos & a. emplastro com fruto cozido & a.5 \\
\hline & & & $\begin{array}{l}\text { b. males do fígado, infecção } \\
\text { nos rins }\end{array}$ & b. flores & b. infusão ou decocção, para beber & b. 2 \\
\hline & & & c. antidiurético & c. folhas & c. infusão ou decocção, para beber & c. 1 \\
\hline Solanum alternatopinnatum Steud. & jequeri & liana & $\begin{array}{l}\text { depurativo do sangue, } \\
\text { limpeza de pele }\end{array}$ & raízes & açúcar raizeiro & 5 \\
\hline \multirow[t]{2}{*}{ Solanum americanum Mill. } & erva-moura & arbustivo & a. cicatrizante da pele & a. folhas & a. infusão ou decocção, para banho & a.3 \\
\hline & & & b. hemorroidas & b. planta inteira & b. vaporização anal & b. 1 \\
\hline Solanum cernuum Vell. & panaceia & arbustivo & pedra nos rins & folhas & infusão ou decocção, para beber & 1 \\
\hline \multirow[t]{5}{*}{ Solanum lycocarpum A. St.-Hil. } & lobeira & arbóreo & a. gripe, tosse, bronquite & a. flores & $\begin{array}{l}\text { a. infusão ou decocção, para beber; } \\
\text { xarope }\end{array}$ & a.7 \\
\hline & & & b. hemorroida & b. flores & b. infusão, para banho de assento & b. 2 \\
\hline & & & c. machucados na pele & c. folhas & c. infusão ou decocção, para banho & c. 1 \\
\hline & & & d. berne, furúnculo & d. frutos & d. emplastro do fruto cozido & d.1 \\
\hline & & & e. infecção nos rins & e. raízes & $\begin{array}{l}\text { e. decocção para banho e para } \\
\text { beber }\end{array}$ & e. 1 \\
\hline **Solanum paniculatum $\mathrm{L}$. & jurubeba & arbustivo & males do fígado & $\begin{array}{l}\text { folhas, } \\
\text { frutos }\end{array}$ & $\begin{array}{l}\text { frutos em conserva ou refogados, } \\
\text { decocção ou infusão das folhas e } \\
\text { flores para beber }\end{array}$ & 7 \\
\hline
\end{tabular}


Continuação do apêndice 1 .

\begin{tabular}{|c|c|c|c|c|c|c|}
\hline Nome científico & Nome popular & Hábito & Usos & Partes utilizadas & Modos de usar & Citações \\
\hline \multicolumn{7}{|l|}{ Verbenaceae } \\
\hline Lantana câmara L. & $\begin{array}{l}\text { cambará, } \\
\text { cambarazinho, } \\
\text { chumbinho }\end{array}$ & arbustivo & gripe, tosse, bronquite & flores & infusão ou decocção, para beber & 5 \\
\hline \multirow{2}{*}{$\begin{array}{l}\text { Stachytarpheta cayennensis (Rich.) } \\
\text { Vahl }\end{array}$} & gervão, geribão & herbáceo & a. gripe, pneumonia & a. raízes & a. infusão ou decocção, para beber & a.2 \\
\hline & & & $\begin{array}{l}\text { b. depurativo do sangue, } \\
\text { limpeza de pele }\end{array}$ & b. raízes & b. açúcar raizeiro & b. 1 \\
\hline \multicolumn{7}{|l|}{ Vochysiaceae } \\
\hline Qualea multiflora Mart. & cavalinho-do-campo & arbóreo & $\begin{array}{l}\text { problemas de pele, herpes, } \\
\text { verme }\end{array}$ & folhas & açúcar raizeiro & 1 \\
\hline \multirow[t]{4}{*}{ Vochysia tucanorum Mart. } & $\begin{array}{l}\text { pau-de-vime, } \\
\text { congonha-de-bugre }\end{array}$ & arbóreo & $\begin{array}{l}\text { a. problemas cardíacos e } \\
\text { infecção nos rins }\end{array}$ & a. casca do tronco & a. decocção, para beber & a. 4 \\
\hline & & & b. fraqueza de criança & b. folhas e resina & b. decocção, para beber & b.4 \\
\hline & & & c. reumatismo & c. folhas e resina & c. decocção, para compressa & c. 4 \\
\hline & & & d. dor de dente & d. resina & d. resina sobre o dente & d.4 \\
\hline \multicolumn{7}{|l|}{ Zingiberaceae } \\
\hline \multirow[t]{5}{*}{ **Costus spicatus (Jacq.) Sw. } & $\begin{array}{l}\text { caninha-do-brejo, } \\
\text { caninha-de-macaco }\end{array}$ & arbustivo & a. inflamação e pedra nos rins & a. folhas e talos & a. decocção, para beber & a.7 \\
\hline & & & b. pressão alta & b. folhas e talos & b. decocção, para beber & b. 2 \\
\hline & & & $\begin{array}{l}\text { c. males do fígado, boca } \\
\text { amarga }\end{array}$ & c. folhas e talos & c. decocção, para beber & c. 1 \\
\hline & & & d. feridas na pele & d. folhas e talos & d. decocção, para beber & d.1 \\
\hline & & & e. tuberculose & e. folhas e talos & e. suco, para beber & e. 1 \\
\hline
\end{tabular}

